\title{
A perspective on therapies for amyotrophic lateral sclerosis: can disease progression be curbed?
}

\author{
Xiaojiao Xu ${ }^{1,4+}$, Dingding Shen ${ }^{2+}$, Yining Gao ${ }^{2}$, Qinming Zhou ${ }^{2}$, You Ni ${ }^{2}$, Huanyu Meng ${ }^{2}$, Hongqin Shi ${ }^{2,3}$, \\ Weidong Le $e^{1,4,5^{*}}$, Shengdi Chen ${ }^{2^{*}}$ and Sheng Chen ${ }^{2^{*}}$ (D)
}

\begin{abstract}
Amyotrophic lateral sclerosis (ALS) is a progressive neurodegenerative disease involving both upper and lower motor neurons, leading to paralysis and eventually death. Symptomatic treatments such as inhibition of salivation, alleviation of muscle cramps, and relief of spasticity and pain still play an important role in enhancing the quality of life. To date, riluzole and edaravone are the only two drugs approved by the Food and Drug Administration for the treatment of ALS in a few countries. While there is adequate consensus on the modest efficacy of riluzole, there are still open questions concerning the efficacy of edaravone in slowing the disease progression. Therefore, identification of novel therapeutic strategies is urgently needed. Impaired autophagic process plays a critical role in ALS pathogenesis. In this review, we focus on therapies modulating autophagy in the context of ALS. Furthermore, stem cell therapies, gene therapies, and newly-developed biomaterials have great potentials in alleviating neurodegeneration, which might halt the disease progression. In this review, we will summarize the current and prospective therapies for ALS.
\end{abstract}

Keywords: Amyotrophic lateral sclerosis, Motor neurons, Autophagy, Stem cells, Gene editing

\section{Introduction}

Amyotrophic lateral sclerosis (ALS), also known as "Lou Gehrig's disease", is a progressive neurodegenerative disease that affects both upper and lower motor neurons (MNs), resulting in paralysis and eventually death generally due to respiratory failure [1-3]. ALS is a rare disease with a reported incidence between $0.8-3.6$ per 100,000 people year, and significant geographical heterogeneity exists $[4,5]$. The median survival time of ALS patients is $3-5$ years since disease onset $[3,6]$. Increasing age and male gender are two major risk factors for ALS, thus

\footnotetext{
* Correspondence: wdle@sibs.ac.cn; chensd@rijh.com.cn; mztcs@163.com ${ }^{+}$Xiaojiao Xu and Dingding Shen contributed equally to this work.

'School of Medicine, University of Electronic Science and Technology of China, Chengdu 610054, China

${ }^{2}$ Department of Neurology, Ruijin Hospital, Shanghai Jiaotong University School of Medicine, Shanghai 200020, China

Full list of author information is available at the end of the article
}

people in the late 50s and men are more susceptible, with a male-to-female ratio of 1.5:1 for ALS incidence $[7,8]$. Apart from age and gender, trauma, cigarette smoking, alcohol consumption, a high fat intake, high levels of premorbid fitness, environmental exposure to heavy metals, pesticides and chemicals, and electric shocks have been reported to be associated with an increased risk of ALS [3, 9-11]. Occupation and education are other two frequently studied factors in ALS. It has been suggested that a low level of education and occupations including veterinarian, athlete, hairdresser, craft and related trades worker, and armed forces personnel might increase the ALS risk $[9,12]$.

Although the clinical hallmark of ALS is progressive motor deficit, the initial symptoms depending on the degree of involvement of upper and lower MNs vary among patients [1]. Approximately $60 \%$ of cases are 
limb-onset, and symptoms are usually asymmetrical in presentation and can first develop in the upper or lower limbs, with muscle weakness and atrophy. Bulbar-onset disease, which is featured by dysarthria and dysphagia, accounts for one-third of ALS patients [13, 14]. The clinical heterogeneity of ALS and the lack of biological diagnostic markers have hindered or delayed appropriate diagnosis. The El Escorial criteria, the consensus guidelines for the diagnosis of ALS which were first established in 1994 and revised in 2000 by Brooks, have been widely accepted $[15,16]$. In this criteria, clinical examination, nerve conduction, electromyography, and laboratory test data are combined to exclude other possible diagnoses. Additionally, the Revised Amyotrophic Lateral Sclerosis Functional Rating Scale (ALSFRS-R), a validated clinical questionnaire-based scale, has been formulated to measure ALS patients' physical function in carrying out activities of daily living, with a lower score usually predicting a poorer prognosis. The ALSF RS-R has been widely used in clinical trials to track progression of the disease and assess the efficacy of drugs [17].

To date, disease-modifying therapies for ALS remain restricted to two drugs, riluzole and edaravone, and they provide only modest clinical benefits [1]. Apart from them, multiple therapies targeting possible disease mechanisms or directly targeting disease-causing genes have been tested in ALS patients or mouse models, showing great potential for future clinical use. The clinical trials of these therapies in ALS are summarized in Table 1. In this article, we will review the recent advances in potential therapeutic strategies for ALS, with a sense of optimism that significant survival improvement could be expected in the future.

\section{Genes and pathogenic mechanisms of ALS}

About $60 \%$ of the risk of ALS can be attributed to the genetics and ALS can be categorized into familial (fALS) and sporadic ALS (sALS) [9, 38], which account for $10 \%$ and 90\% of ALS cases, respectively [1]. More than 30 genes have been identified in fALS $[8,39]$, of which mutations in genes encoding superoxide dismutase 1 (SOD1), chromosome 9 open reading frame 72 (C9orf72), TAR DNA binding proteins (TARDBP/TDP43) and fused in sarcoma (FUS) account for at least 50\% of all fALS cases [14, 40]. Mutations in SOD1, the first identified gene in fALS, occur in up to $20 \%$ of fALS cases and $1 \%-4 \%$ of sALS cases. SOD $1^{\mathrm{G} 93 \mathrm{~A}}$ mice are the most commonly used model in ALS studies investigating molecular mechanisms and evaluating drug efficacy [41].

Although the precise mechanisms underlying ALS remain unclear, many pathologic processes have been implicated, including glutamate excitotoxicity, protein misfolding and aggregation, impaired protein degradation (involving impairment of autophagy and proteasome), oxidative stress, axonal transport abnormalities, inflammation, aberrant RNA metabolism, mitochondrial dysfunction, and endoplasmic reticulum (ER) stress $[1,13,14,42]$.

Genetic polymorphism can potentially modify drug response, an effect named pharmacogenomics. In an analysis of genetic interaction between three common ALSrelated genes and creatine monohydrate and valproic acid treatment in two clinical trials, a dose-response pharmacogenetic interaction between creatine and the A allele of the MOBP genotype (rs616147) was identified, highlighting the importance of incorporating genetic information in ALS clinical trials [43].

\section{Current clinical treatments}

Over the past two decades, more than 50 drugs have shown efficacy in extending life expectancy in preclinical animal models of ALS [14]. Yet, there is still no cure for ALS that could reverse the progression of this disorder from a clinical perspective. Riluzole and edaravone are the only two disease-modifying drugs for the treatment of ALS [1, 13, 44, 45].

\section{Riluzole}

Riluzole is a glutamate release inhibitor that blocks voltage-gated sodium channels, and is the first drug approved by FDA for ALS treatment in 1995 [1]. So far, there has been adequate consensus on the modest efficacy of riluzole. Recently, reanalysis of case records of all 959 participants from a previous dose-ranging trial showed that higher-dose riluzole $(100 \mathrm{mg} /$ day $)$ prolonged stage 4 in patients with ALS instead of slowing the entire disease course or prolonging stage 2 or 3 [46]. Results from other trials have suggested greater benefits from riluzole treatment at early stage before the occurrence of significant degeneration of MNs [47, 48]. Fan et al. have investigated the effect of daily and cumulative riluzole in a long-term follow-up of an ALS cohort in China [49] and reported a better prognosis in patients receiving the cumulative defined daily dose of riluzole higher than $16,800 \mathrm{mg}$ than other groups, highlighting the importance of long-term riluzole use.

\section{Edaravone}

Edaravone is a free radical scavenger that has been approved for the treatment of ALS in a few countries (approved in Japan in 2015, South Korea in 2015, the United States in 2017, Canada in 2018, Switzerland in 2019, China in 2019, and Indonesia in 2020) [44, 50]. Edaravone has demonstrated effects in reducing oxidative stress and delaying functional motor deterioration in a previous clinical study [51]. However, a phase III confirmatory trial (MCI 186-16) has failed to demonstrate 
Table 1 Clinical trials in recent 10 years

\begin{tabular}{|c|c|c|c|c|c|c|}
\hline $\begin{array}{l}\text { Clinical trial } \\
\text { identifier }\end{array}$ & $\begin{array}{l}\text { Phase } \\
\text { /subjects }\end{array}$ & Drug & Treatment & Duration & $\begin{array}{l}\text { Primary outcome } \\
\text { measure }\end{array}$ & Main findings \\
\hline \multicolumn{7}{|l|}{ Oxidative stress } \\
\hline $\begin{array}{l}\text { NCT00330681/ } \\
{[18]}\end{array}$ & $\begin{array}{l}\text { Phase III } \\
206 \\
\text { participants }\end{array}$ & $\begin{array}{l}\text { Edaravone } \\
\text { (MCl-186) }\end{array}$ & $\begin{array}{l}\text { Placebo }(n=104) \text { or edaravone } \\
(n=102) \text { i.v. infusion over } 60 \\
\text { min for the first } 14 \text { days in } \\
\text { cycle } 1 \text {, and for } 10 \text { of the first } \\
14 \text { days during cycles } 2 \text { to } 6 .\end{array}$ & $\begin{array}{l}2006.05- \\
2008.09\end{array}$ & ALSFRS-R & $\begin{array}{l}\text { Small reduction of ALSFRS-R } \\
\text { scores was observed in the } \\
\text { edaravone group. }\end{array}$ \\
\hline $\begin{array}{l}\text { NCT01492686/ } \\
{[19]}\end{array}$ & $\begin{array}{l}\text { Phase III } \\
137 \\
\text { participants }\end{array}$ & $\begin{array}{l}\text { Edaravone } \\
\text { (MCl-186) }\end{array}$ & $\begin{array}{l}\text { Placebo }(n=69) \text { or edaravone } \\
(n=68) \text { i.v. infusion over } 60 \mathrm{~min} \\
\text { for the first } 14 \text { days in cycle } 1 \\
\text { and for } 10 \text { of the first } 14 \text { days } \\
\text { during cycles } 2 \text { to } 6 .\end{array}$ & $\begin{array}{l}2011.12- \\
2014.9\end{array}$ & ALSFRS-R & $\begin{array}{l}\text { Edaravone improved ALSFRS-R } \\
\text { scores in a small subset of } \\
\text { people. }\end{array}$ \\
\hline \multicolumn{7}{|l|}{ Autophagy } \\
\hline $\begin{array}{l}\text { UMIN000036295/ } \\
{[20]}\end{array}$ & Phase I & Bosutinib & $\begin{array}{l}\text { Three to six patients with ALS } \\
\text { were enrolled at each of the } \\
\text { four bosutinib dose levels ( } 100 \text {, } \\
200,300 \text { or } 400 \text { mg/day). }\end{array}$ & $\begin{array}{l}2019.03- \\
2021.03\end{array}$ & DLT & Undergoing. \\
\hline $\begin{array}{l}\text { NCT02166944/ } \\
{[21]}\end{array}$ & $\begin{array}{l}\text { Phase } 1 / \| \\
20 \\
\text { participants }\end{array}$ & Tamoxifen & $\begin{array}{l}\text { Tamoxifen } 40 \mathrm{mg}(n=10) \text { or } \\
\text { riluzole }(n=8) \text { daily for } 1 \text { year. }\end{array}$ & $\begin{array}{l}2014.04- \\
2019.09\end{array}$ & ALSFRS-R & $\begin{array}{l}\text { Tamoxifen exerted only a } \\
\text { modest effect in attenuating } \\
\text { progression for } 6 \text { months. }\end{array}$ \\
\hline
\end{tabular}

$\begin{array}{ll}\text { NCT01640067/ } & \text { Phase I HSSCS } \\ {[22]} & 18 \\ & \text { participants }\end{array}$

$\begin{array}{lll}\text { NCT01348451/ } & \text { Phase I HSSCS } \\ \text { [23] } & 18 \\ & \text { participants } & \\ & \\ & \\ \text { NCT01730716/ } & \begin{array}{l}\text { Phase II HSSCS } \\ {[24]}\end{array} & \begin{array}{l}18 \\ \text { participants }\end{array}\end{array}$

$\begin{array}{ll}\text { NCT01640067/ } & \text { Phase I hNSCs } \\ \text { [25] } & 18 \\ & \text { participants }\end{array}$

$\begin{array}{ll}\text { NCT01363401/ } & \text { Phase I/II BM- MSCs } \\ {[26,27]} & 72 \\ & \text { participants }\end{array}$

$\begin{array}{lll}\text { NCT01051882/ } & \text { Phase I/II NurOwn } \\ \text { [28] } & 12 \\ & \text { participants } & \\ & \\ \text { NCT01777646/ } & \text { Phase lla NurOwn } & \\ {[28]} & 14 & \\ & \text { participants }\end{array}$

Three received 3 unilateral injections of hNSCs into the lumbar cord tract, while the others received bilateral injections. A total of 750,000 cells per injection site $(15 \mu)$.

2011.12- Treatment-related

Ten microliters were delivered at a rate of $5 \mu \mathrm{l} / \mathrm{min}$ over $2 \mathrm{~min}$ by unilateral cervical injections, for a total of 500,000 cells (NSI566RSC HSSC line) in the 5 injections.

Three participants in each group. The numbers of injection (site: C3-C5 or L2-L4 bilateral injections) ranged from 10 to 40 , and the numbers of cells (HSSCs) injected ranged from 2 million to 16 million.

Participants were divided into 3 2011.12- Treatment-related groups with monolateral or bilateral injections (C3-C5 or T8T11) of a total of 750,000 cells (15 $\mu$ hNSCs) per injection.

Each participant received 2 intrathecal injections of autologous BM-MSCs $\left(1 \times 10^{6}\right.$ cells/kg) 26 days apart. Control group ( $n=31$, riluzole $100 \mathrm{mg}$ alone).

Six patients in each group received i.m. or i.t. injection of NurOwn ${ }^{\oplus}$.

Fourteen patients received combined i.t. and i.m. delivery. (IM at 24 sites to the biceps 2015.12 mortality, AEs, neuroradiological and neurophysiological variables

Transplantation of hNSCs was confirmed to be a safe cell therapy approach with good reproducibility.

Transient improvement in ALSF RS-R and MRC was observed in some patients.

2009.01- AES

Safety and feasibility of cervical and dual-targeting approaches (both lumbar and cervical injection) was demonstrated.

2013.05- AEs 2016.11 2015.12 mortality, AEs, neuroradiological and neurophysiological variables

\subsection{2- ALSFRS-R} 2013.08

2011.06- Safety evaluation and tolerability.

2012.12- Safety evaluation 2015.09 and tolerability
Intraspinal transplantation of HSSCs was safe at high doses (20 injections, 400,000 cells/ injection), including successive lumbar and cervical injections.

Safety of hNSC transplantation was confirmed.

A transitory decrease in progression of ALSFRS-R was observed, starting within the first month after surgery and up to 4 months after transplantation.

Two repeated intrathecal injections were safe and feasible throughout the 12month duration.

Safe and well-tolerated.

Improvement in the decrease rate of progression of the FVC and ALSFRS-R was 
Table 1 Clinical trials in recent 10 years (Continued)

\begin{tabular}{|c|c|c|c|c|c|c|}
\hline $\begin{array}{l}\text { Clinical trial } \\
\text { identifier }\end{array}$ & $\begin{array}{l}\text { Phase } \\
\text { /subjects }\end{array}$ & Drug & Treatment & Duration & $\begin{array}{l}\text { Primary outcome } \\
\text { measure }\end{array}$ & Main findings \\
\hline & & & $\begin{array}{l}\text { and triceps }\left(1 \times 10^{6} \text { cells } / \text { site); }\right. \\
\left.\text { i.t. of } 1 \times 10^{6} \text { cells } / \mathrm{kg}\right)\end{array}$ & & & $\begin{array}{l}\text { demonstrated in the i.t. (or } \\
\text { i.t. + i.m.)-treated groups. }\end{array}$ \\
\hline $\begin{array}{l}\text { NCT02017912/ } \\
{[29]}\end{array}$ & $\begin{array}{l}\text { Phase II } \\
48 \\
\text { participants }\end{array}$ & MSC-NTF cells & $\begin{array}{l}\text { MSC group }(n=36) \text { : MSC-NTF } \\
\text { cells. Placebo }(n=12) \text { : Dulbecco } \\
\text { Modified Eagle Medium. } \\
\text { Combination of i.t. }\left(125 \times 10^{6}\right. \\
\text { cells) and } 24 \text { i.m. }\left(48 \times 10^{6} \text { cells) }\right. \\
\text { injections of NurOwn }{ }^{\oplus} \text { at } 24 \\
\text { sites to the biceps and triceps }\end{array}$ & $\begin{array}{l}2014.05- \\
2016.07\end{array}$ & AEs & $\begin{array}{l}\text { In a prespecified rapid } \\
\text { progressor subgroup }(n=21) \text {, } \\
\text { the rate of disease progression } \\
\text { was improved at early time } \\
\text { points. }\end{array}$ \\
\hline $\begin{array}{l}\text { NCT02286011/ } \\
{[30]}\end{array}$ & $\begin{array}{l}\text { Phase I } \\
20 \\
\text { participants }\end{array}$ & MNC of BM & $\begin{array}{l}\text { Experimental group: an } \\
\text { intramuscular infusion of } \\
\text { autologous MNC of bone BM } \\
\text { in TA muscle of one of the } \\
\text { lower limbs (100-1200 million) } \\
\text { diluted in } 2 \mathrm{ml} \text { saline. }\end{array}$ & $\begin{array}{l}2014.11- \\
2017.12\end{array}$ & AEs & $\begin{array}{l}\text { The intramuscular injection of } \\
\text { BMMCs was safe and had an } \\
\text { effect on the D50 index. }\end{array}$ \\
\hline $\begin{array}{l}\text { NCT03241784/ } \\
{[31]}\end{array}$ & $\begin{array}{l}\text { Phase I } \\
4 \\
\text { participants }\end{array}$ & $\begin{array}{l}\text { Autologous T- } \\
\text { regulatory } \\
\text { lymphocytes }\end{array}$ & $\begin{array}{l}\text { A total of } 8 \text { infusions of } \\
\text { autologous Tregs }\left(1 \times 10^{6} \text { cells/ }\right. \\
\mathrm{kg} \text { ) with concomitant } \\
\text { subcutaneous } \mathrm{IL}-2 \text { injections ( } 3 \\
\text { times / week, } 2 \times 10^{5} \mathrm{IU} / \mathrm{m}^{2} / \\
\text { injection). }\end{array}$ & $\begin{array}{l}2016.05- \\
2018.02\end{array}$ & AEs & $\begin{array}{l}\text { The numbers of Tregs and } \\
\text { suppressive function increased } \\
\text { after infusion and the increased } \\
\text { suppressive function of Tregs } \\
\text { correlated with slowing of } \\
\text { progression rate. }\end{array}$ \\
\hline
\end{tabular}

\section{Gene modification}

$\begin{array}{lll}\text { NCT01041222/ } & \text { Phase I } & \text { ISIS 3336 } \\ \text { [32] } & 33 & \\ & \text { participants } & \\ & & \\ & & \\ \text { NCT02623699/ } & \text { Phase I/II } & \text { Tofersen } \\ {[33]} & \begin{array}{l}84 \\ \text { participants }\end{array} & \text { (BIIB067) }\end{array}$

Four cohorts of eight patients 2010.01- Safety, received intrathecal infusion of 2012.01 pharmacokinetics ISIS 333611 at dose of $0.15 \mathrm{mg}$, $0.5 \mathrm{mg}, 1.5 \mathrm{mg}, 3 \mathrm{mg}$, respectively (randomized 6 drugs: 2 placebo/cohort).

In each dose cohort $(20,40,60$, or $100 \mathrm{mg}$ ), participants were randomly assigned in a 3:1 ratio to receive five doses of tofersen or placebo, administered intrathecally for 12 weeks.

\section{Excitotoxicity}

NCT00444613/

[34]

Phase II/III

373

Mecobalamin

participants

2007.04- Survival rate, ALSF 2014.03 RS-R
(E0302)

Placebo $(n=124), 25 \mathrm{mg}(n=$ 124) or $50 \mathrm{mg}$

methylcobalamin $(n=125)$ administered intra-muscularly twice a week for 182 weeks.

\section{Mitochondrial defects and apoptosis}

$\begin{array}{lll}\text { NCT01786603/ } & \text { Phase II } & \text { Rasagiline } \\ \text { [35] } & 80 \\ & \text { participants } & \\ & \\ & \\ \text { NCT01879241/ } & \text { Phase II Rasagiline } \\ {[36]} & \begin{array}{l}252 \\ \end{array} & \text { participants }\end{array}$

\section{Immunomodulatory}

$\begin{array}{ll}\text { NCT02588677/ } & \text { Phase II/III Masitinib } \\ \text { [37] } & 394 \\ & \text { participants }\end{array}$

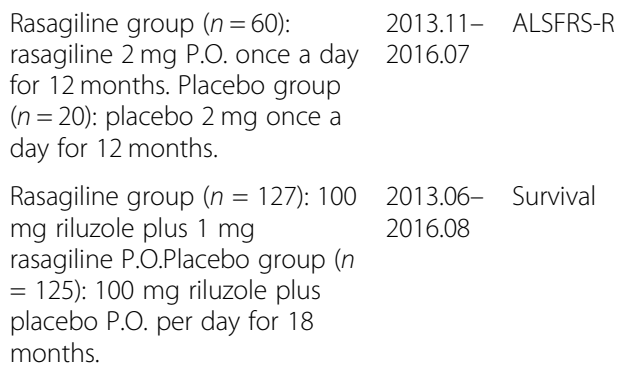

Rasagiline group $(n=60): \quad$ 2013.11- $\quad$ ALSFRS-R

rasagiline $2 \mathrm{mg}$ P.O. once a day 2016.07

2013.06- Survival 2016.08

394 patients were randomly assigned (1:1:1) to receive riluzole $(100 \mathrm{mg} / \mathrm{d})$ plus placebo or masitinib at 4.5 or $3.0 \mathrm{mg} / \mathrm{kg}$ per day.

2013.04- ALSFRS-R
2018.03

No dose-limiting toxicity was found at doses up to $3.0 \mathrm{mg}$. Dose-dependent CSF and plasma concentrations were observed.

CSF SOD1 concentrations decreased at the highest concentration of tofersen administered intrathecally over a period of 12 weeks.

No significant efficacy was seen in the whole cohort. The treatment may prolong survival and retard symptomatic progression if started early (s12 months' duration).

Rasagiline was well tolerated with no serious adverse events. No improvement in the ALSF RS-R slope was observed in the rasagiline group.

Disease progression might be modified by rasagiline in patients with normal to fast progression rate, despite no efficacy in survival.

Masitinib showed significant benefits over placebo with a between-group difference in $\triangle$ ALSFRS-R, corresponding to $27 \%$ slowing in the rate of 
Table 1 Clinical trials in recent 10 years (Continued)

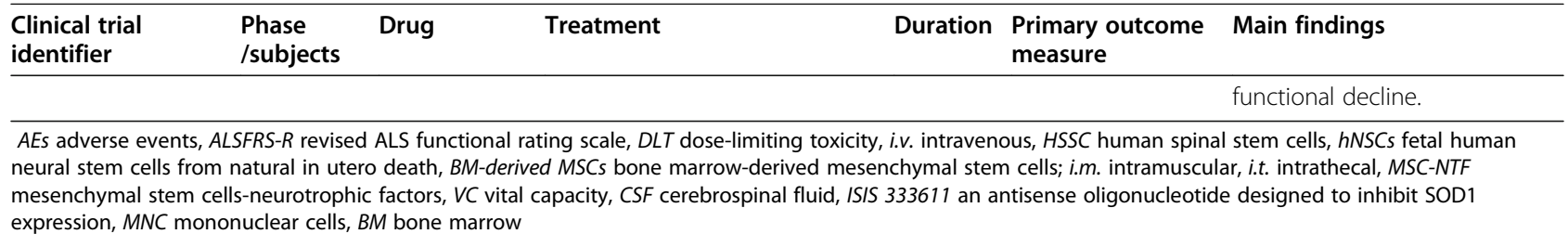

the efficacy of edaravone in the prolongation of survival and respiratory function improvement [18]. Subsequent post-hoc analysis of the MCI 186-16 trial revealed a positive effect of edaravone in a restricted subgroup with milder symptoms and a disease duration within 2 years, and the effect could last for over a period of 24 weeks [52]. Notably, in a second phase III trial (MCI 186-19, NCT01492686) in which patients were well defined by strict inclusion criteria, the edaravone group showed a significant improvement in the ALSFRS-R score when compared with the placebo group, suggesting a beneficial effect of edaravone for over 24 weeks [19]. However, a latest study in Italian ALS patients has demonstrated no significant difference between Edaravone-treated and control groups in either disease progression or respiratory function [53]. Considering that edaravone has just been approved in certain countries for a few years, and few clinical trials carried out in recent years have demonstrated the beneficial effect of edaravone, the efficacy of edaravone in ALS treatment remains controversial. Hence, further clinical studies with stringent inclusion criteria, long duration, and reliable pathobiological markers are urgently required to validate the efficacy of edaravone.

\section{Other symptomatic treatments}

ALS patients suffer from a wide range of debilitating symptoms, including fatigue, cramps, spasticity, dysphagia, respiratory insufficiency, sleep disorders, pain, psychosocial morbidity, etc. Supportive care plays an important role in providing symptom management and improving quality of life. The symptoms of ALS could be relieved by pharmacological and non-pharmacological interventions. Thus, multidisciplinary ALS care alleviating the symptoms can enhance the quality of life and prolong the survival of patients [14]. Expert consensus guidelines for supportive and symptomatic management of ALS are available [2]. However, high-quality evidence for the effectiveness of symptomatic therapies is very limited. Double-blind, placebo-controlled studies are available for only a few symptomatic treatments, such as botulinum toxin for sialorrhea [54] and dextromethorphan plus quinidine for pseudobulbar affect [55].

Spasticity is a common symptom present in most patients with ALS. Muscle relaxants such as baclofen and tizanidine should only be used for disabling spasticity because of the side effects of aggravation of muscle weakness and the sedating effect $[2,56]$. Baclofen could be administered through an intrathecal pump if oral administration is ineffective [57]. Additionally, cannabinoids may have potential value in the treatment of spasticity in ALS patients, as they can control spasticity with safety and efficacy in multiple sclerosis [58, 59]. Most recently, a placebo-controlled phase II trial has demonstrated that nabiximols, a combination of tetrahydrocannabinol and cannabidiol, have a positive antispastic and pain-relieving effect in patients with motor neuron disease [60]. Furthermore, a retrospective monocentric cohort study has revealed high treatment satisfaction with nabiximols, suggesting that nabiximols are an addition to ALS symptomatic therapy [61]. Preclinical studies have also shown neuroprotective effects of cannabinoids, such as reducing excitotoxicity and oxidative damage, and suppressing neuroinflammation and microglial activation by activating CB1 and particularly CB2 receptors. Besides, application of cannabinoids can delay motor impairment and prolong survival in murine models [62-64]. Taken together, these data demonstrate the great potential of cannabinoids in ALS as a supplement therapy.

Respiratory failure is the leading cause of death in ALS. Non-invasive ventilation has shown benefits of prolonging survival by 7 months and improving the quality of life in an earlier small randomized controlled trial (RCT) including 41 ALS patients [65], and the FDA approved diaphragmatic pacing as a weakened diaphragm stimulator for ALS treatment in 2011 [2]. However, a more recent multicenter, open-label RCT (ISRC TN 53817913) demonstrated that addition of diaphragm pacing to standard care with non-invasive ventilation was associated with decreased survival and should not be used as a treatment for ALS patients [66]. Similar results were reported in another multicenter trial (NCT01583088) [67]. Recently, mexiletine has been tested for its efficacy in ALS due to its effect in reducing muscle cramps in Machado-Joseph disease. Although results showed no effect on the functional disability, impairment and survival in ALS, mexiletine induced a significant improvement in muscle cramp severity and frequency $[68,69]$. 


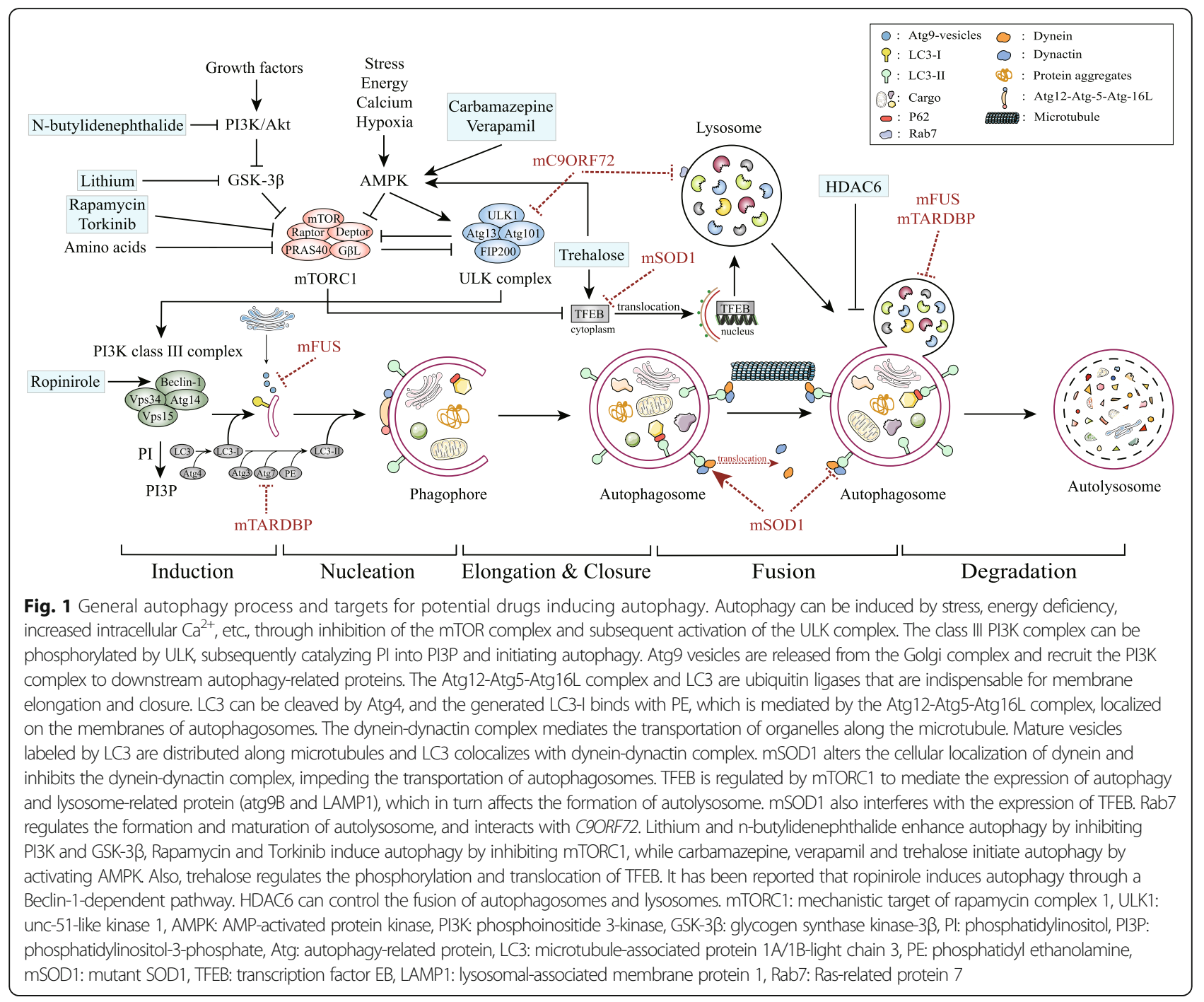

Weight loss and malnutrition are common features of ALS. Reduced survival time and poor quality of life correlate with the nutritional status of ALS patients [70]. The European Federation of Neurological Societies guidelines recommend gastrostomy for ALS patients with severe dysphagia when weight loss reaches at least $10 \%$ from premorbid weight. A recent large, longitudinal, prospective cohort study enrolling 345 ALS patients has shown no difference in the safety regarding survival and procedural complications among three methods of gastrostomy, and that the median survival (12 months) after gastrostomy for patients with weight loss of $10 \%$ or less from that at diagnosis was increased by about 4 months when compared with those who had lost more than $10 \%$ of their weight from diagnosis $(7.7$ months) [71]. This finding indicates that less than $10 \%$ of weight loss might be an optimum timing for gastrostomy insertion to achieve clinical benefits. Yu et al. enrolled 272 Korean sporadic ALS patients to investigate the relationship between dietary fiber intake and the prognosis of ALS. Kaplan-Meier analysis showed a significant distinction in the mean survival time according to vegetable fiber intake, with patients in the highest tertile of vegetable fiber intake showing a longer survival and a lower rate of disease progression. Moreover, the vegetable fiber intake is negatively correlated with the level of pro-inflammatory cytokines (interleukin [IL]-1 $\beta$, IL-6 and monocyte chemoattractant protein-1) in the cerebrospinal fluid (CSF) [72]. Therefore, dietary fiber supplementation intervention could be included into ALS clinical trials to further validate its efficacy in improving prognosis of ALS.

\section{Prospective disease-modifying therapies Autophagy-targeting therapies}

Autophagy, a catabolic and recycling process that eliminates dysfunctional organelles and abnormal protein aggregates in the cell, is essential to neuronal homeostasis. 
Impaired autophagy represents a critical pathomechanism in ALS, and autophagic regulation is therefore emerging as a potential therapeutic strategy for ALS (Fig. 1) [73].

\section{Rapamycin}

The mammalian target of rapamycin (mTOR) pathway is the best-characterized regulator of autophagy initiation. Rapamycin, a widely used autophagy enhancer by inhibiting the mTOR pathway, has presented controversial effects in different genetic animal models of ALS, which limits its practical use in ALS treatment [74-76].

\section{Trehalose}

Trehalose is a natural disaccharide that induces mTORindependent autophagy. Administration of trehalose has been shown to prolong the lifespan and delay the disease onset in SOD1 ${ }^{\text {G86R }}$ mice, accompanied by reduced SOD1 accumulation and enhanced MN survival in the spinal cord [77]. Similar therapeutic effects have been demonstrated in a SOD $1^{\mathrm{G} 93 \mathrm{~A}}$ mouse model of ALS [78], but the efficacy diminishes during later stages of the disease [79].

\section{Lithium}

Although effective in delaying the disease onset and extending the lifespan in different ALS mouse models by regulating the mTOR-independent pathway [80-82], lithium failed to show therapeutic benefits in ALS patients in previous clinical trials [83-87]. However, a recent metaanalysis on the different responses between genotypes has found that the treatment effect of lithium is not homogenous across patients. Patients carrying UNC13A (protein unc-13 homolog A) mutation could benefit more from lithium treatment than C9orf 72 mutation carriers, with 12-month survival probability improving from $40.1 \%$ to $69.7 \%$. This result provides a new insight for future clinical trials and suggests that we should start focusing on genotype-targeted therapies and standardize genotyping due to the heterogeneity of ALS [88].

\section{$\mathrm{N}$-butylidenephthalide}

$\mathrm{N}$-butylidenephthalide is the main component of a traditional Chinese medicine Danggui. It can regulate autophagy by mediating ER stress [89]. Oral administration of $250 \mathrm{mg} / \mathrm{kg}$ (bid) n-butylidenephthalide before the onset of the disease has shown a better effect on survival than riluzole in an ALS mouse model [90]. Furthermore, administration of n-butylidenephthalide could decrease MN loss and restore the gastrocnemius function of $\mathrm{SOD} 1^{\mathrm{G} 93 \mathrm{~A}}$ mice. These neuroprotective effects may be associated with the inhibition of autophagy through the Akt/mTOR signaling pathway, and anti-apoptosis, anti-inflammation and antioxidative effects [91].

\section{Carbamazepine}

Carbamazepine is a well-known anti-epileptic drug that has been reported to stimulate autophagy by decreasing the intracellular level of inositol [92]. Carbamazepine could activate autophagy via the mTOR-independent pathway and rescue the motor dysfunction of frontotemporal lobar dementia (FTLD-U) mice with TDP-43 proteinopathies [75]. In SOD1 ${ }^{\text {G93A }}$ mice, oral administration of carbamazepine $(200 \mathrm{mg} / \mathrm{kg}$ per day) could delay the disease onset and significantly extend survival. In addition, carbamazepine increases the clearance of mutant SOD1 aggregates via the AMPK-ULK1 pathway, which plays a protective role in the preservation of MNs [93].

\section{W. somnifera}

$W$. somnifera is a perennial herb containing the component Withaferin A which has been reported to have a beneficial effect in both TDP-43 and SOD ${ }^{\text {G93A }}$ mouse models [94, 95] and increase autophagosomes [96]. Recent studies have proven that W. somnifera has the same effect as Withaferin A and can serve as an autophagyinducer $[97,98]$.

\section{Verapamil}

Previous studies have demonstrated that the elevated level of cytosolic $\mathrm{Ca}^{2+}$ in ALS MNs is associated with autophagy regulation in a mTOR-independent manner. Verapamil is a L-type $\mathrm{Ca}^{2+}$ channel blocker used clinically for cardiovascular diseases. It can activate autophagy and improve autophagy influx by reducing intracellular $\mathrm{Ca}^{2+}$. In the SOD1 ${ }^{\mathrm{G} 93 \mathrm{~A}}$ mouse model, intraperitoneal injection with verapamil $(25 \mathrm{mg} / \mathrm{kg}$ per day) could delay the disease onset and extend survival by improving autophagy influx and reducing SOD1 aggregation [99].

\section{Torkinib}

Stress granules play an important role in regulating the formation of insoluble aggregates in pathological conditions [100]. Recently, Torkinib, a selective mTOR inhibitor, has been demonstrated to reverse the pathological changes of stress granules in induced pluripotent stem cell (iPSC)-derived neurons with P525L FUS mutation, which is one of the most severe mutations of ALS [101].

\section{Bosutinib and Ropinirole}

Bosutinib and ropinirole are two candidate anti-ALS drugs recently identified in iPSC-based drug screens and are now under clinical investigation [102]. Bosutinib, an inhibitor of $\mathrm{Src} / \mathrm{c}-\mathrm{Abl}$, has been found to increase the survival of ALS iPSC-derived MNs by inducing autophagy and reducing misfolded SOD1 and TDP-43 proteins. Furthermore, bosutinib has been shown to delay disease onset and prolong survival of SOD1-mutant mice [103]. A 12-week phase I dose-escalation trial has been 
initiated in ALS subjects (UMIN000036295) to evaluate the safety and tolerability of bosutinib at 4 levels (100, 200, 300 or $400 \mathrm{mg} /$ day) [20]. Ropinirole, an agonist of dopamine D2 and D3 receptor (D2R/D3R), has shown a mitochondrion-targeted antioxidant effect in iPSCderived ALS MNs. Recent reports have demonstrated that agonists of D2R/D3R might promote autophagy through a Beclin-1-dependent pathway [102]. It would be interesting to determine whether the ropiniroleinduced D2R/D3R activation leads to degradation of abnormal RNA-protein complexes via autophagy activation in ALS MNs.

\section{Tamoxifen}

Pathologic TDP-43 accumulation is one of the typical pathophysiological manifestations in ALS. Tamoxifen has been validated to enhance autophagy through the mTORdependent pathway by inhibiting $\mathrm{AKT} / \mathrm{PKB}$ and increase the clearance of TDP-43 aggregates. A small phase II clinical trial initiated to explore the efficacy of tamoxifen in ALS patients has been completed in Taipei (NCT02166944). Among 18 patients, 10 of them were randomly assigned to receive tamoxifen treatment $(40 \mathrm{mg}$ daily for 1 year). According to the result from the first 6month follow-up, a slower decline rate of ALSFRS-R score was observed in the tamoxifen group, though there was no difference in the ALSFRS-R score between the two groups at the 12-month follow-up. This outcome demonstrated a modest effect of tamoxifen in slowing progression during 6-month follow-up. Given the small-scale of this trial, larger-scale trials are required for a robust conclusion on tamoxifen efficacy [21].

\section{Histone deacetylase 6 (HDAC6)-targeting strategy}

HDAC6 plays an essential role in the regulation of mutant SOD1 aggregation [104, 105] and controls the fusion of autophagosomes to lysosomes [106]. While some studies have demonstrated detrimental effects associated with HDAC6 inhibition, a recent study showed that overexpression of HDAC6 in ALS mice could prolong the lifespan by inducing the formation of autolysosomes and the degradation of mutant SOD1 protein aggregates [107]. In another study, genetic ablation of HDAC6 increases the number of remaining neurons in the ventral horn of the spinal cord, along with a significant improvement in the survival of SOD ${ }^{\text {G93A }}$ mice [108].

\section{Cell-based therapies}

Accumulating evidence has supported the idea that transplantation of stem cells may become a promising alternative therapy for ALS [109, 110]. Transplanted stem cells could secrete growth factors such as glial cellderived neurotrophic factor (GDNF), brain-derived neurotrophic factor (BDNF), vascular endothelial growth factor (VEGF), and insulin-like growth factor-1 to provide neurotrophic support and slow the degeneration of MNs $[110,111]$. To date, several types of stem cell with various properties and therapeutic effects have been used in preclinical and clinical trials for ALS. Among them, neural stem/ precursor cells (NSCs/NPCs), mesenchymal stem cells (MSCs) and hematopoietic stem cells (HSCs) are most widely used.

\section{NSCs/NPCs}

In a recent study, clinical-grade human NSCs (hNSCs) were bilaterally transplanted into the anterior horns of the lumbar spinal cord of SOD1 mutant rats (4 sites, L3-4 segment), and 40 days after the transplantation, the hNSCs integrated extensively within the cord, presented with neural phenotypes, and migrated from the injection site for $3.77 \pm 0.63 \mathrm{~cm}$. More importantly, the transplantation delayed the decrease of body weight and the deterioration of motor performance, reduced the level of astroglial and microglial activation, and increased the density of MNs [112]. In another study, transplantation of hNSCs engineered to secrete glial cell line-derived GDNF into the SOD1 ${ }^{\text {G93A }}$ ALS rat cortex induced a delay of disease pathology and prolongation of survival without adverse effects. This demonstrates that the motor cortex could also be a transplant site in addition to the spinal cord [113]. Previous clinical studies have confirmed the safety and feasibility of intrathecal NSC transplantation [22-24]. The combined lumbar (L2-L4) and cervical cord (C3-C5) injections at 20 sites (400,000 cells/injection) have proven to be safe and well-tolerated in 15 participants without acceleration of the disease progression, which indicates that intrathecal transplantation of hNSCs can be safely accomplished at high doses (NCT01730716) [24]. Consistently, a recent phase I clinical trial (NCT01640067) using a highly standardized cell drug product has obtained the same results and underscored good reproducibility and homogeneity of stable hNSCs lines. The potential therapeutic effects of hNSCs have provided sufficient promise for future phase II trials, which are currently in preparation by the same group [25]. Once the therapeutic effect and safety of this standardized cell drug product are firmly verified, it is promising to address thorny issues related to ethics and source restrictions in the future.

\section{MSCs}

MSCs can be obtained from bone marrow, peripheral blood, umbilical cord blood and adipose tissue. The relative ease of in vivo harvesting and expansion of patientderived MSCs has allowed their wide application by cell transplantation in studies of neurologic diseases with less risk of rejection and fewer ethical issues [112]. 
Multiple intracerebroventricular transplantation of MSCs $(250,000$ hUC-MSCs resuspended in $8 \mu$ of sterile PBS) isolated from the human umbilical cord protected MNs but had no beneficial effects on the survival of ALS mice [114]. The safety and feasibility of MSC transplantation in the central nervous system have been demonstrated by a phase I clinical trial. In that trial, expanded autologous MSCs suspended in the autologous CSF were injected into the thoracic spinal cord. After transplantation, no structural or pathologic change was observed in the central nervous system (CNS) as revealed by MRI scanning [115]. Further phase I and II clinical studies have been conducted to investigate the safety of repeated intrathecal injection of MSCs from human bone marrow. Results have shown increased TGF- $\beta$ and IL-10 as well as reduced MCP-1 expression, which are related to MN injury, suggesting that intrathecal injection of MSCs may modulate immunoinflammation in ALS patients $[26,27]$. In the phase II study (NCT01363401), two repeated treatments with intrathecal autologous bone marrow-derived MSCs $\left(1 \times 10^{6}\right.$ cells/kg with a 26 -day interval) showed significant therapeutic benefits with safety in ALS patients [27]. MSCs can be induced to offer enhanced secretion of neurotrophic factors (GDNF, BDNF, VEGF), and the treated MSCs were developed as a cell product called MSC-NTF or NurOwn by BrainStorm Cell Therapeutics in 2007 [116]. In a phase I/II and a IIa clinical trials (NCT01051882 and NCT01777646), intramuscular or intrathecal administration of NurOwn is safe and well-tolerated. Furthermore, possible clinical benefits were observed in patients with intrathecal administration, or combined intrathecal and intramuscular administration [28]. Recently, a phase II RCT (NCT02017912) tested the single-dose transplantation of MSC-NTF cells, and found a higher proportion of treated participants (combined intrathecal and intramuscular administration) with $\geq 1.5$ points/month ALSF RS-R slope improvement, increased neurotrophic factors and decreased inflammatory biomarkers after transplantation, in addition to a good safety, suggesting promising efficacy of NurOwn transplantation [29]. Another phase I/II clinical trial (NCT02286011) selected the tibialis anterior muscle as a transplant site, and found that single injection of BM-MSCs (ranging $206 \times 10^{6}-1086 \times 10^{6}$ cells) was safe and caused a higher D50 index, a parameter used to quantify the compound muscle action potential scan curve which decreases with disease severity [30]. As muscle is predominantly affected in ALS, retarding the progressive loss of motor units and denervation atrophy may improve the functional outcome or survival. Therefore, direct intramuscular implantation combined with intrathecal injection may be more effective and need to be assessed in future trials.
Respiratory dysfunction is the most common cause of death in ALS patients $[3,6]$. Numerous microhemorrhages caused by microvasculature impairment have been observed in SOD1 ${ }^{\text {G93A }}$ mice at the late stage, which may cause respiratory complications in ALS [117]. Microvasculature impairment is relevant to the damage of microvessel endothelial cells. In SOD1 ${ }^{\mathrm{G} 93 \mathrm{~A}}$ mice with hemorrhagic damage in the lung, intravenous transplantation of BM-MSCs attenuates endothelium damage through the re-establishment of vascular integrity by BM-MSCs. The transplanted cells could also release VEGF, angiogenin, and vesicles to promote angiogenesis in the lung and mediate intercellular communication [117].

\section{HSCs}

Neuroinflammation characterized by activation of neuroglia cells and infiltration of peripheral monocytes and lymphocytes is increasingly being recognized as a key pathogenic feature of ALS [118]. Regulatory T lymphocytes (Tregs) are a subpopulation of immunosuppressive $\mathrm{T}$ lymphocytes, and their dysfunction has been demonstrated in ALS patients $[119,120]$. HSCs are multipotent cells that have the potential to differentiate into all mature cell types in blood, and the transplantation of HSCs has been proven to suppress inflammation and modulate immune response [116, 121]. HSC transplantation has been used for clinical treatment for a long time, and the ease of collection from peripheral blood or bone marrow, together with the non-invasive nature of administration, has made it a reliable treatment for ALS [116, 122]. Transplantation of bone marrow which could reconstitute Tregs has exerted positive effects on survival in an ALS mouse model by modulating the trophic/cytotoxic balance of glia [123]. Recently, a phase I, first-inhuman study (NCT03241784) found that autologous infusion of expanded Tregs was safe and well-tolerated in all three patients. After a total of 8 infusions of expanded autologous Tregs $\left(1 \times 10^{6}\right.$ cells $\left./ \mathrm{kg}\right)$ with concomitant subcutaneous IL-2 injections (once a week, $2 \times 10^{5} \mathrm{IU} /$ $\mathrm{m}^{2}$ ) that help enhance the proliferation and function of infused Tregs, slowing of progression rate was observed at both early and later stages of the disease. Meanwhile, the increased suppressive function of Tregs showed a positive correlation with the slowing of clinical progression, supporting the value of Tregs suppressive function as an indicator of clinical status [31].

Despite the numerous preclinical and clinical studies demonstrating safety and therapeutic benefits in ALS patients and animal models, large, prospective RCTs with long-term follow-up are still needed to identify the safety, efficacy and optimal dose of these therapies [124, 125]. 


\section{Gene therapies}

Gene therapies are used to replace or correct a defective gene involved in disease pathogenesis. The latest strategies developed to suppress the expression of mutated genes include anti-sense oligonucleotides (ASOs), RNA interference (RNAi) and CRISPR-Cas9 genome editing system [126].

\section{ASOs}

ASOs are short oligonucleotide sequences that selectively target and bind mRNA to interfere with its processing or transduction in many different ways, thereby preventing or modifying the expression of toxic protein. ASOs can induce cleavage of RNA by activating endogenous, intranuclear RNase $\mathrm{H}$ or preventing the interaction with specific RNA-binding proteins, thereby modulating its splicing [127]. In 2016, nusinersen (Spinraza) for spinal muscular atrophy became the first FDAapproved ASO-based therapy for neurodegenerative diseases [128]. In a phase I trial (NCT01041222), an ASO designed to inhibit SOD1 expression (ISIS 333611) was delivered by a single intrathecal infusion (L3-4) for $11 \mathrm{~h}$ and 22 min using an infusion pump at increasing doses (0.15 mg, $0.5 \mathrm{mg}, 1.5 \mathrm{mg}, 3 \mathrm{mg}$ ), and results showed that it was safe and well-tolerated [32]. ASOs can also effectively decrease the expression of SOD1 mRNA and protein in the CSF and brain of SOD $1^{\text {G93A }}$ rat model [129]. Recently, a single dose of next-generation SOD1 ASOs has shown a positive effect on the survival of SOD1 ${ }^{\text {G93A }}$ rats and mice, which was prolonged by 50 days and 40 days, respectively. Furthermore, it turned out that the initial loss of compound muscle action potential could also be reversed in SOD1 ${ }^{\mathrm{G} 93 \mathrm{~A}}$ mice [130]. Hexanucleotide expansions in C9ORF72 are a common genetic cause for ALS and frontotemporal dementia (FTD). Previous studies have shown that ASOs could suppress RNA foci formation and gene expression and abrogate the C9ORF72 RNA expansion-dependent pathology, the aggregation of RNA-binding proteins and the glutamatemediated excitotoxicity in fibroblasts and humanderived iPSC neurons [127, 131, 132]. In C9ORF72 transgenic mice, cerebroventricular injection of singledose ASOs could reduce RNA foci and dipeptide-repeat proteins, and ameliorate behavioral deficits [133]. Ataxin 2 gene is also associated with the risk of ALS. Administration of ASOs targeting ataxin 2 in the CNS of TDP43 mice could greatly extend the survival and improve the motor performance of the mice [134].

The ASO-based therapy has shown great potential in preclinical studies. More recently, a phase I-II ascending-dose trial (NCT02623699) was conducted to evaluate the safety, pharmacokinetics and pharmacodynamics of tofersen in ALS cases carrying SOD1 mutation [33]. Tofersen is an ASO that reduces
SOD1 protein synthesis by mediating the degradation of SOD1 mRNA. In that trial, 48 participants were randomly assigned to receive different doses of tofersen (20 mg, $40 \mathrm{mg}, 60 \mathrm{mg}$, or $100 \mathrm{mg}$ ) or placebo by lumbar intrathecal bolus injection on days 1, 15, 29, 57, and 85. The total SOD1 protein concentration in the CSF was reduced in the four dose cohorts. The change of CSF SOD1 concentration at day 85 from that at baseline in the tofersen groups differed from the placebo group by $2 \%,-25 \%,-19 \%$, and $-33 \%$, respectively. Moreover, in the fast-progression subgroup, the ALSFRS-R score of the $100 \mathrm{mg}$ tofersen group seemed to decrease slower than the placebo group [33]. For further investigation of the safety and efficacy of tofersen, a phase III, randomized, doubleblind, placebo-controlled trial (NCT02623699) and its long-term extension study (NCT03070119) are currently underway.

\section{RNAi}

RNAi is another approach against RNA-mediated gain of toxicity, in which long double-stranded RNA duplexes are first processed within the cell and loaded into an RNA-induced silencing complex (RISC). The binding of RISC and the targeted cellular mRNA will then silence the mRNA by RNase-mediated degradation or translational repression [135]. RNAi can be induced by small RNA duplexes, and the three most common duplexes are artificial microRNA (miRNA), short interfering RNAs, and short hairpin RNAs (shRNAs) [135]. Due to the blood-brain barrier (BBB), viral vectors derived from lentivirus and adeno-associated virus (AAV) are used for therapeutic gene delivery [136]. In an animal study, neonatal SOD1 ${ }^{\text {G93A }}$ mice receiving injection of a singlestranded AAV9 vector encoding an artificial mRNA against human SOD1 in the cerebral lateral ventricles showed improvements in multiple parameters including survival, number of MNs, the extent of neuroinflammation, diameter of ventral root axons and pulmonary function [137]. Similar results have been demonstrated in another study [138]. A recent study has demonstrated that the AAV5-delivered artificial miRNAs targeting C9orf72 could reduce the accumulation of repeatcontaining C9orf72 transcripts in both iPSC-derived neurons and ALS mouse model [139, 140]. Although an allele-specific silencing effect has been observed through intrathecal or intraventricular delivery of the vector, there are still some limitations in the delivery method. To improve the penetrability of the viral delivery vectors, high titers are required, which limits the feasibility, effectiveness, and safety of this gene silencing therapy. An excellent work using a spinal subpial method to deliver AAV9-mediated shRNA targeting SOD1 has provided a potent approach for transduction of neurons and 
surrounding glia and showed higher efficiency in reducing SOD1 $1^{\text {G37R }}$-encoding mRNA than the intrathecal injection method [141]. Additionally, the spinal subpial delivery method shows an impressive effect in delaying disease onset and stopping disease progression in $S O D 1^{G 37 R}$ mice [141]. Therefore, seeking appropriate delivery methods should also be viewed as an important part of future studies.

The safety and efficacy of RNAi-based therapies has been tested predominantly in preclinical models of ALS. Recently, two ALS patients with SOD1 mutation were treated with a single intrathecal infusion of AAV encoding a miRNA targeting SOD1 [142]. Unfortunately, patient 1 died from respiratory failure 15.6 months after the initiation of treatment. Autopsy results of patient 1 revealed lower SOD1 levels in the spinal cord than in the untreated patients. In addition, transient and slight reduction of SOD1 levels in the CSF was observed in patient 1. Although having no change in the CSF SOD1 level, the patient 2 had stable functional status and vital capacity for 12 months [142]. In general, this study demonstrated that intrathecal miRNA might be a promising treatment for ALS. However, due to the heterogeneity of ALS and the insufficient sample size, confirmative conclusions on treatment effects could not be drawn.

\section{CRISPR-Cas9 genome-editing system}

The CRISPR/Cas9 genome editing system is emerging as a promising tool to disrupt the expression of mutant genes at the genomic level. CRISPR/Cas9 is a type II CRISPR/Cas system with guide RNA to target specific DNA sequences and with Cas9 as a nuclease [143]. CRISPR/Cas9 has already been successfully used to establish gene-corrected ALS iPSCs [144]. Moreover, when delivered by the AAV vector in SOD $1^{\text {G93A }}$ mice, CRISPR/Cas9 could disrupt expression of mutant SOD1 and reduce the protein level of mutant SOD1 in the spinal cord, accompanied by prolonged survival and improved motor function [126, 143]. RNA-targeting Cas9 has been reported to be able to reduce RNA foci and polyglutamine protein products in the C9orf72-linked ALS patient cells [145]. In the C9orf72-linked ALS cell line, transcriptional inhibition mediated by deactivated Cas9 could rescue the splicing defects and block the repeat-associated non-ATG translation to reduce toxic dipeptide polymers [146]. In addition, increased expression of the GluA1 AMPA receptor (AMPAR) subunit observed in iPSC-derived MNs with C9ORF72 mutations, but not in iPSC-derived cortical neurons, is rescued by CRISPR/Cas9-mediated correction of the C9ORF72 repeat expansion in MNs, together with the abolishment of increased $\mathrm{Ca}^{2+}$-permeable AMPAR expression and $\mathrm{MN}$ vulnerability to excitotoxicity caused by the increased GluA1 subunit [130]. Andrade et al. have reported that dipeptide repeat proteins (DPRs) encoded by C9ORF72 through a non-canonical translation mechanism are neurotoxic and can increase the frequency of DNA double-strand breaks (DSBs) by inhibiting the key DNA DSB repair pathways. It is noteworthy that the accumulation of DNA DSBs is reduced and the dysregulation of single-strand annealing is improved after deletion of C9ORF72 expansion by CRISPR/Cas9 in C9ALS iPSC lines [147]. These results indicate that genome editing is the best approach to correcting disease-causing mutations. However, the safety, target specificity, immunogenicity as well as ethical concerns need to be addressed before translation to clinical use.

\section{Limitations of gene therapies for ALS}

ALS is a lethal neurodegenerative disorder without effective treatment. Heritability research has demonstrated that about $60 \%$ of the risk of ALS is genetically determined $[9,38]$ and mutations in more than 25 genes have been found in patients with or without a family history $[148,149]$. In recent years, the development of gene therapy techniques and clinical application of the nusinersen-based therapy targeting spinal muscular atrophy have demonstrated great potentials of gene therapies in treatment of neurological disorders, suggesting that the gene editing approach may hold promise for ALS treatment. To date, applications of gene therapies in ALS have mainly focused on C9ORF72 correction. C9ORF72 repeat expansion is identified as the most common genetic cause for ALS and FTD. Abnormal translation of the expanded repeat will result in loss of function, RNA toxicity, and DPR protein toxicity that are implicated in pathogenesis, thus gene-editing techniques targeting causal mutations to cut repeat expansions, inhibit transcription, or selectively reduce the repeat-containing RNAs might be promising in retarding disease progression. The effectiveness of the ASO and RNAi therapies in reducing RNA foci has been observed in vitro and in vivo $[127,131,139,140]$. Based on these results, a phase I clinical trial of ASOs targeting the sense strand of C9ORF72 in C9 ALS patients has been conducted (NCT03626012). In addition, genetic correction of C9ORF72 repeat expansions has been seen in patient iPSCs $[130,147]$. These encouraging results suggest that gene editing is a promising tool for treating ALS patients carrying a single gene mutation. However, previous reports of oligogenic inheritance in ALS indicate that the early-onset patients may carry more than one ALS gene mutation [150]. In this situation, the effect of gene therapies targeting an individual mutation might become suboptimal. More importantly, the genetic heterogeneity of ALS and the limited numbers of identified genes in sALS patients make the personalized gene 
therapy more challenging and it is impossible to design clinical trials targeting each specific gene. However, the genetic mutations can be categorized into several subgroups that share a common mechanism of pathology, providing an opportunity for therapies. On the other hand, in the loss-of-function ALS subgroups, gene delivery strategies aiming to normalize the function of the mutated protein may be within reach. In addition, safety issues such as off-target effects and inactivation of the normal gene copy remain to be solved before clinical use. Currently, there is no effective treatment for ALS, and the inspiring results from ASOs and RNAi-based therapies in both preclinical and clinical studies are raising hope for ALS treatment.

\section{Others}

\section{Mito $Q$}

Mito $\mathrm{Q}$ is an antioxidant that has been shown to mitigate oxidative damage in neurodegenerative disease models. Mito Q can accumulate within mitochondria and improve mitochondrial function in different neuronal cells exposed to oxidative stress [151]. Mitochondrial dysfunction is involved in the pathogenesis of ALS, and impaired mitochondrial function has been observed in the SOD1 mouse model. Previous studies have shown that pretreatment of SOD $1^{\text {G93A }}$ astrocytes with Mito Q prevents the toxicity of mutant SOD1 and improves ATP generation in MNs [39, 152]. Moreover, Mito Q orally administered $(500 \mu \mathrm{M})$ in SOD $1^{\mathrm{G} 93 \mathrm{~A}}$ mice since the presentation of early symptoms significantly preserves the neuromuscular junctions and increases the strength of hindlimbs by improving mitochondrial function and decreasing nitroxidative damage in the lumbar spinal cord and the quadriceps muscle. The extension of lifespan suggests that administration of Mito Q may slow the disease process [153].

\section{Methylcobalamin}

Methylcobalamin, physiologically equivalent to vitamin B12, shows a protective effect against glutamateinduced cytotoxicity in cultured cortical neurons [154]. Multivitamin therapy with vitamin B12 and folic acid significantly delays disease onset and prolongs the average lifespan of SOD $1^{\mathrm{G} 93 \mathrm{~A}}$ transgenic mice [155]. In addition, a retard in the progression of motor symptoms and neuropathological changes has been observed in wobbler mice after intraperitoneal treatment with high-dose methylcobalamin [156]. In a recently reported phase II/III clinical trial (NCT00444613) on the safety and efficacy of intramuscular ultra-high-dose methylcobalamin in ALS patients, primary endpoints of survival and ALSFRS-R change both failed to show a difference between methylcobalamin (25 and $50 \mathrm{mg}$ ) and placebo groups. However, post-hoc analyses demonstrated that $50 \mathrm{mg}$ methylcobalamin prolonged survival and retarded symptomatic progression when administered at an early stage ( $\leq 12$ months after symptom onset) [34].

\section{Rasagiline as an add-on therapy to riluzole}

Rasagiline, a monoamine oxidase B inhibitor with a symptomatic efficacy in Parkinson's disease, prolongs survival in preclinical animal studies of ALS, both alone and in combination with riluzole [157]. In a small US study with 80 ALS patients and 177 historical placebo controls, rasagiline $(2 \mathrm{mg} /$ day $)$ alone neither altered disease progression nor showed evidence for biomarker engagement [35]. Albert Ludolph and colleagues conducted a phase II RCT (NCT01879241) of rasagiline (1 $\mathrm{mg} /$ day) as an add-on treatment to riluzole in 252 ALS patients. No difference in the primary outcome of survival was observed between the rasagiline and placebo groups. However, post-hoc stratifications revealed a possible survival benefit and slower functional decline in a subset of patients with an initial slope of ALSFRS-R greater than 0.5 points per month [36].

\section{Masitinib as an add-on therapy to riluzole}

Masitinib, a targeted anticancer drug, has shown therapeutic potential in SOD1 ${ }^{\text {G93A }}$ mice via its immunomodulatory properties targeting microglia as well as macrophage activity in both CNS and peripheral nervous system. The efficacy of masitinib as an add-on therapy to riluzole has been assessed in a phase II/III clinical trial over a 48-week treatment period (NCT02588677), in which 394 ALS patients were randomly assigned to receive riluzole $(100 \mathrm{mg} /$ day $)$ plus placebo or masitinib (3.5 or $4.5 \mathrm{mg} / \mathrm{kg}$ per day). Compared with the placebo group, riluzole plus masitinib $(4.5 \mathrm{mg} / \mathrm{kg}$ per day) showed a significant $27 \%$ slowing in rate of functional decline [37]. Significant results were also found for secondary endpoints such as ALSAQ-40, FVC and time-toevent analysis [37].

\section{AMX0035}

AMX0035, a combination of sodium phenylbutyrate and taurursodiol, was designed to attenuate neuronal death by mitigating ER stress and bioenergetic dysfunction. In a multicenter, phase 2, placebo-controlled trial (CENTAUR) that evaluated the efficacy of oral AMX0035 in ALS patients, there was a significant difference of 0.42 points per month between the active-drug group and the placebo group in the mean rate of change in the ALSF RS-R total score over 6 months, representing an approximately $25 \%$ slowing of disease progression [158]. In the open-label extension of CENTAUR, random assignment to AMX0035 at baseline resulted in a 6.5-month survival advantage compared with the placebo assignment [159]. 


\section{Nanotechnology-based strategies}

Although a wide variety of therapeutic agents have proven effective in ALS preclinical studies and some are undergoing clinical investigation, their efficacy is still suboptimal and far from satisfactory due to the challenges regarding safe and effective delivery routes. These challenges can be attributed to the $\mathrm{BBB} / \mathrm{blood}$-spinal cord barrier, as well as insufficient biostability/bioavailability and "off-target" effects. Encouragingly, the development of nanotechnology-based strategies allows for the improvement of therapies in, e.g., effective delivery of drugs, genes and ASOs to the CNS, and promoting the effectiveness of stem cell therapies $[160,161]$.

For example, Bondi and collaborators have employed solid lipid nanoparticles as a drug carrier for riluzole, and found that riluzole carried by solid lipid nanoparticles accumulates less in the nontarget organs [162]. Besides, the concentration of riluzole tested in the rat brain is significantly higher when using solid lipid nanoparticles as a delivery system [162]. Shashi et al. encapsulated riluzole in tween80-coated, chitosan-conjugated $\mathrm{N}$ isopropylacrylamide nanoparticles and found that the nanoriluzole could effectively cross the BBB and exhibit neuroprotective effect by reducing the expression of inflammatory molecules and increasing the glutathione level at a very low concentration [163]. Liposomes, also known as liposomal nanoparticles, have been employed by Yang et al. to overcome the pharmaco-resistance problem and improve the transportation of riluzole in the CNS. They found that the verapamil and riluzole cocktail liposomes could suppress the function of efflux transporters and improve the uptake of riluzole in an in vitro BBB cell model [164]. Similar effects have been achieved for edaravone encapsulated into agonistic micelles [165].

Therapies targeting gene defects, such as the RNAi and ASOs technologies, are greatly limited by the delivery barriers. AAV and lentivirus are the most common carriers used in present studies; however, concerns on safety, immunogenicity, expression time of exogenous genes as well as the package and isolation of the virus have interfered with their clinical use and therapeutic effect. In 2017, calcium phosphate lipid-coated nanoparticles (CaP-lipid NPs) were developed for the delivery of SOD1 ASO to MNs [166]. The particles have an encapsulation efficiency of $48 \%$ for ASO and remain stable for more than 20 days. The CaP-lipid NPs can effectively deliver SOD1-targeting ASOs into the NSC-34 cell line and suppress SOD1 expression in HEK293 cells [166]. Moreover, the CaP-lipid NPs can be efficiently delivered to the CNS of zebrafish and have a prolonged circulation time within the bloodstream, which indicates that nanoparticles may become an ideal delivery system for gene therapy [166].
Biomaterials can also be used in stem cell-based therapies to provide a more permissive microenvironment for stem cell growth and distribution, and allow visualization of intrathecal delivery and targeted cell placement process. The use of high-speed MRI could track the stem cell infusion process in real-time when MSCs are labeled by superparamagnetic iron oxide nanoparticles, which can ensure placement of stem cells in defined brain regions and avoid formation of potentially dangerous cell aggregates [167]. Besides nanoparticles, hydrogels have also demonstrated potentials as cell delivery vehicles and imaging probes in ALS treatment $[168,169]$. Human-derived adipose stem cells encapsulated in formulations of methacrylated gellan gum/hyaluronic acid hydrogel blends could stay in vitro for over 14 days and be visible as a hyperintense signal in $\mathrm{T} 1$ MRI for $24 \mathrm{~h}$ after transplantation in vivo [169]. Hydrogel exhibits great strengths in improving biodistribution and providing physical support for stem cells to enhance their survival, which makes it a promising tool for injectable image-guided cell delivery approaches $[168,169]$.

\section{From bench to bedside: bottlenecks in translating preclinical studies in ALS and future directions}

Great efforts have been made in search for effective therapies for ALS throughout the years. Based on the promising results in preclinical cellular and animal models, hundreds of agents have been proposed as candidates for ALS treatment. However, clinical trials have predominantly come to disappointing results in humans. Several obstacles are implicated in the failure of translation from bench to bedside in the field of ALS treatment.

First, the inadequacy of ALS models is considered as an important reason for failed clinical trials. At the preclinical level, genetically modified rodents carrying fALS mutations remain the most widely used models. However, they do not fully recapitulate the complete pathophysiological and phenotypic spectrum present in ALS patients. ALS is caused by defects in different interacting pathways that culminate in a large network. The relative extent to which each of these mechanisms contributes to the overall pathobiology of ALS has not been fully ascertained, making it difficult to discriminate initiating factors from secondary consequences and target the primary processes underlying ALS. A more comprehensive understanding of ALS pathogenic mechanisms will allow for advances in treatment.

Second, the lack of presymptomatic biomarkers and the delay in clinical diagnosis have significantly limited the therapeutic potential of putative disease-modifying drugs. It is now increasingly accepted that by the time patients fulfil the diagnostic criteria for ALS, a considerable disease burden has already occurred in the long 
presymptomatic phase. The timing of application of potentially neuroprotective interventions is fundamental for increasing the chance of success. The results of treatment that was started much in advance with respect to the onset of symptoms in animal models should be considered as indicative of success in humans. Presymptomatic diagnosis and clinical trials of early therapeutic intervention in fALS patients identified to carry ALS-related gene mutations are strongly recommended in the future. Also, potential biomarkers that allow early intervention to improve therapeutic outcomes of ALS are anticipated in the near future.

\section{Conclusions and comments}

There is an urgent need to develop novel diseasemodifying therapeutics to slow the disease progression and extend the lifespan of ALS patients. Since emerging evidence has supported the notion that dysregulation of autophagy is critical for the pathogenesis of ALS, the autophagic signal pathway may be a potential therapeutic target. Furthermore, studies elucidating the genotypephenotype correlations in ALS patients in recent years have laid ground for individualized, gene-specific therapeutic approaches. The results of these studies advance our understanding of ALS and boost our hope that disease progression can be curbed in the future.

\section{Abbreviations}

ALS: Amyotrophic lateral sclerosis; MNs: Motor neurons; fALS: Familial amyotrophic lateral sclerosis; SALS: Sporadic amyotrophic lateral sclerosis; SOD1: Superoxide dismutase 1; C9orf72: Chromosome 9 open reading frame 72; TARDBP/TDP43: TAR DNA-binding proteins; ER: Endoplasmic reticulum; ALSFRS-R: Amyotrophic Lateral Sclerosis Functional Rating Scale Revised; mTOR: Mammalian target of rapamycin kinase; HDAC6: Histone deacetylase 6; GSK-3 $\beta$ : Glycogen synthase kinase-3 $\beta$; Atg: Autophagy-related protein; LC3: Microtubule-associated protein 1A/1B-light chain 3; PE: Phosphatidyl ethanolamine; TFEB: Transcription factor EB; LAMP1: Lysosomal-associated membrane protein 1; Rab7: Ras-related protein 7; GDNF: Glial cell-derived neurotrophic factor; BDNF: Brain-derived neurotrophic factor; VEGF: Vascular endothelial growth factor; NSC/NPCs: Neural stem/ precursor cells; MSCs: Mesenchymal stem cells; HSCs: Hematopoietic stem cells; CNS: Central nervous system; ASOs: Anti-sense oligonucleotides; RNAi: RNA interference; CSF: Cerebrospinal fluid; PSC: Induced pluripotent stem cell; RISC: RNAinduced silencing complex; miRNA: MicroRNA; shRNAs: Short hairpin RNAs; AAV: Adeno-associated virus; AMPAR: AMPA receptor; DPRs: Dipeptide repeat proteins; DSBs: Double-strand breaks; BBB: Blood-brain barrier; CaP-lipid NPs: Calcium phosphate lipid-coated nanoparticles

\section{Acknowledgements}

We thank Dr. Stanly H. Appel, Edwards Distinguished Endowed Chair for ALS Research Chair and Co-Director of Houston Methodist Neurological Institute for his critical review of this revised manuscript.

\section{Authors' contributions}

Xiaojiao Xu and Dingding Shen conceived the review and drafted the manuscript. Yining Gao, Qinming Zhou, You Ni, Huanyu Meng, and Hongqin Shi, Weidong Le, Shengdi Chen, and Sheng Chen helped with editing and modifying the manuscript. Sheng Chen designed this review. All the authors read and approved the manuscript.

\section{Funding}

This review work was supported by funding from the National Nature Research Foundation (81671241, 81771521); Shanghai Shuguang Plan Project (18SG15) and Shanghai outstanding young scholars Project.

Availability of data and materials

All the data mentioned in this article are available in published article.

\section{Declarations}

Ethics approval and consent to participate

Not applicable.

\section{Consent for publication}

Not applicable.

\section{Competing interests}

Shengdi Chen is Editor-in-Chief of the journal and was not involved in the peer-review process of this article.

\section{Author details}

${ }^{1}$ School of Medicine, University of Electronic Science and Technology of China, Chengdu 610054, China. 'Department of Neurology, Ruijin Hospital, Shanghai Jiaotong University School of Medicine, Shanghai 200020, China. ${ }^{3}$ Department of Neurology, Xinrui Hospital, Wuxi 214028, China. ${ }^{4}$ Institute of Neurology, Sichuan Academy of Medical Sciences-Sichuan Provincial Hospital, Chengdu 610031, China. ${ }^{5}$ Center for Clinical Research on Neurological Diseases, the First Affiliated Hospital, Dalian Medical University, Dalian 116021, China.

Received: 4 February 2021 Accepted: 9 July 2021

Published online: 10 August 2021

References

1. Oskarsson B, Gendron TF, Staff NP. Amyotrophic lateral sclerosis: an update for 2018. Mayo Clin Proc. 2018:93:1617-28.

2. Hobson EV, McDermott CJ. Supportive and symptomatic management of amyotrophic lateral sclerosis. Nat Rev Neurol. 2016;12:526-38..

3. Paez-Colasante X, Figueroa-Romero C, Sakowski SA, Goutman SA, Feldman EL. Amyotrophic lateral sclerosis: mechanisms and therapeutics in the epigenomic era. Nat Rev Neurol. 2015;11:266-79.

4. GBD 2016 Neurology Collaborators. Global, regional, and national burden of motor neuron diseases 1990-2016: a systematic analysis for the Global Burden of Disease Study 2016. Lancet Neurol. 2018;17:1083-97.

5. Longinetti E, Fang F. Epidemiology of amyotrophic lateral sclerosis: an update of recent literature. Curr Opin Neurol. 2019;32:771-6.

6. Chen L, Zhang B, Chen R, Tang L, Liu R, Yang Y, et al. Natural history and clinical features of sporadic amyotrophic lateral sclerosis in China. J Neurol Neurosurg Psychiatry. 2015;86:1075-81.

7. Niedermeyer $S$, Murn M, Choi PJ. Respiratory failure in amyotrophic lateral sclerosis. Chest. 2019;155:401-8.

8. Bonafede R, Mariotti R. ALS pathogenesis and therapeutic approaches: the role of mesenchymal stem cells and extracellular vesicles. Front Cell Neurosci. 2017:11:80

9. Al-Chalabi A, Hardiman O. The epidemiology of ALS: a conspiracy of genes, environment and time. Nat Rev Neurol. 2013;9:617-28.

10. Huisman MH, Seelen M, van Doormaal PT, de Jong SW, de Vries JH, van der Kooi AJ, et al. Effect of presymptomatic body mass index and consumption of fat and alcohol on amyotrophic lateral sclerosis. JAMA Neurol. 2015;72: $1155-62$.

11. Yu X, Wang T, Chen Y, Shen Z, Gao Y, Xiao L, et al. Alcohol drinking and amyotrophic lateral sclerosis: an instrumental variable causal inference. Ann Neurol. 2020;88:195-8

12. Sutedja NA, Veldink JH, Fischer K, Kromhout H, Wokke JH, Huisman MH, et al. Lifetime occupation, education, smoking, and risk of ALS. Neurology. 2007;69:1508-14.

13. van Es MA, Hardiman O, Chio A, Al-Chalabi A, Pasterkamp RJ, Veldink JH, et al. Amyotrophic lateral sclerosis. Lancet. 2017;390:2084-98.

14. Hardiman O, Al-Chalabi A, Chio A, Corr EM, Logroscino G, Robberecht W, et al. Amyotrophic lateral sclerosis. Nat Rev Dis Primers. 2017;3:17071. 
15. Brooks BR. El Escorial World Federation of Neurology criteria for the diagnosis of amyotrophic lateral sclerosis. Subcommittee on Motor Neuron Diseases/Amyotrophic Lateral Sclerosis of the World Federation of Neurology Research Group on Neuromuscular Diseases and the El Escorial "Clinical limits of amyotrophic lateral sclerosis" workshop contributors. J Neurol Sci. 1994;124(Suppl):96-107.

16. Brooks BR, Miller RG, Swash M, Munsat TL. El Escorial revisited: revised criteria for the diagnosis of amyotrophic lateral sclerosis. Amyotroph Lateral Scler Other Motor Neuron Disord. 2000;1:293-9.

17. Cedarbaum JM, Stambler N, Malta E, Fuller C, Hilt D, Thurmond B, et al. The ALSFRS-R: a revised ALS functional rating scale that incorporates assessments of respiratory function. BDNF ALS study group (phase III). J Neurol Sci. 1999:169:13-21.

18. Abe K, Itoyama Y, Sobue G, Tsuji S, Aoki M, Doyu M, et al. Confirmatory double-blind, parallel-group, placebo-controlled study of efficacy and safety of edaravone (MCl-186) in amyotrophic lateral sclerosis patients. Amyotroph Lateral Scler Frontotemporal Degener. 2014;15:610-7.

19. Abe K, Aoki M, Tsuji S, Itoyama Y, Sobue G, Togo M, et al. Safety and efficacy of edaravone in well defined patients with amyotrophic lateral sclerosis: a randomised, double-blind, placebo-controlled trial. Lancet Neurol. 2017;16:505-12.

20. Imamura K, Izumi Y, Banno H, Uozumi R, Morita S, Egawa N, et al. Induced pluripotent stem cell-based drug repurposing for amyotrophic lateral sclerosis medicine (iDReAM) study: protocol for a phase I dose escalation study of bosutinib for amyotrophic lateral sclerosis patients. BMJ Open. 2019;9:e033131.

21. Chen PC, Hsieh YC, Huang CC, Hu CJ. Tamoxifen for amyotrophic lateral sclerosis: A randomized double-blind clinical trial. Medicine (Baltimore). 2020;99:e20423.

22. Mazzini L, Gelati M, Profico DC, Sgaravizzi G, Projetti Pensi M, Muzi G, et al. Human neural stem cell transplantation in ALS: initial results from a phase I trial. J Transl Med. 2015;13:17

23. Feldman EL, Boulis NM, Hur J, Johe K, Rutkove SB, Federici T, et al. Intraspinal neural stem cell transplantation in amyotrophic lateral sclerosis: phase 1 trial outcomes. Ann Neurol. 2014;75:363-73.

24. Glass JD, Hertzberg VS, Boulis NM, Riley J, Federici T, Polak M, et al. Transplantation of spinal cord-derived neural stem cells for ALS: analysis of phase 1 and 2 trials. Neurology. 2016;87:392-400.

25. Mazzini L, Gelati M, Profico DC, Soraru G, Ferrari D, Copetti M, et al. Results from phase I clinical trial with intraspinal injection of neural stem cells in amyotrophic lateral sclerosis: a long-term outcome. Stem Cells Transl Med. 2019:8:887-97.

26. Oh KW, Moon C, Kim HY, Oh SI, Park J, Lee JH, et al. Phase I trial of repeated intrathecal autologous bone marrow-derived mesenchymal stromal cells in amyotrophic lateral sclerosis. Stem Cells Transl Med. 2015:4:590-7.

27. Oh KW, Noh MY, Kwon MS, Kim HY, Oh SI, Park J, et al. Repeated intrathecal mesenchymal stem cells for amyotrophic lateral sclerosis. Ann Neurol. 2018; 84:361-73

28. Petrou P, Gothelf Y, Argov Z, Gotkine M, Levy YS, Kassis I, et al. Safety and clinical effects of mesenchymal stem cells secreting neurotrophic factor transplantation in patients with amyotrophic lateral sclerosis: results of phase 1/2 and 2a clinical trials. JAMA Neurol. 2016;73:337-44.

29. Berry JD, Cudkowicz ME, Windebank AJ, Staff NP, Owegi M, Nicholson K, et al. NurOwn, phase 2, randomized, clinical trial in patients with ALS: safety, clinical, and biomarker results. Neurology. 2019;93:2294-305.

30. Geijo-Barrientos E, Pastore-Olmedo C, De Mingo P, Blanquer M, Gómez Espuch J, Iniesta F, et al. Intramuscular injection of bone marrow stem cells in amyotrophic lateral sclerosis patients: a randomized clinical trial. Front Neurosci. 2020;14:195.

31. Thonhoff JR, Beers DR, Zhao W, Pleitez M, Simpson EP, Berry JD, et al. Expanded autologous regulatory T-lymphocyte infusions in ALS: A phase I, first-in-human study. Neurol Neuroimmunol Neuroinflamm. 2018:5:e465.

32. Miller TM, Pestronk A, David W, Rothstein J, Simpson E, Appel SH, et al. An antisense oligonucleotide against SOD1 delivered intrathecally for patients with SOD1 familial amyotrophic lateral sclerosis: a phase 1, randomised, first-in-man study. Lancet Neurol. 2013;12:435-42.

33. Miller T, Cudkowicz M, Shaw PJ, Andersen PM, Atassi N, Bucelli RC, et al. Phase 1-2 trial of antisense oligonucleotide tofersen for SOD1 ALS. N Engl J Med. 2020;383:109-19.

34. Kaji R, Imai T, Iwasaki Y, Okamoto K, Nakagawa M, Ohashi Y, et al. Ultra-highdose methylcobalamin in amyotrophic lateral sclerosis: a long-term phase
II/III randomised controlled study. J Neurol Neurosurg Psychiatry. 2019;90: $451-7$.

35. Statland JM, Moore D, Wang Y, Walsh M, Mozaffar T, Elman L, et al. Rasagiline for amyotrophic lateral sclerosis: A randomized, controlled trial. Muscle Nerve. 2019;59:201-7.

36. Ludolph AC, Schuster J, Dorst J, Dupuis L, Dreyhaupt J, Weishaupt JH, et al. Safety and efficacy of rasagiline as an add-on therapy to riluzole in patients with amyotrophic lateral sclerosis: a randomised, double-blind, parallelgroup, placebo-controlled, phase 2 trial. Lancet Neurol. 2018;17:681-8.

37. Mora JS, Genge A, Chio A, Estol CJ, Chaverri D, Hernández M, et al. Masitinib as an add-on therapy to riluzole in patients with amyotrophic lateral sclerosis: a randomized clinical trial. Amyotroph Lateral Scler Frontotemporal Degener. 2020:21:5-14.

38. Al-Chalabi A, Fang F, Hanby MF, Leigh PN, Shaw CE, Ye W, et al. An estimate of amyotrophic lateral sclerosis heritability using twin data. J Neurol Neurosurg Psychiatry. 2010;81:1324-6.

39. Vandoorne T, De Bock K, Van Den Bosch L. Energy metabolism in ALS: an underappreciated opportunity? Acta Neuropathol. 2018;135:489-509.

40. Nassif M, Valenzuela V, Rojas-Rivera D, Vidal R, Matus S, Castillo K, et al. Pathogenic role of BECN1/Beclin 1 in the development of amyotrophic lateral sclerosis. Autophagy. 2014:10:1256-71.

41. Chen S, Sayana P, Zhang X, Le W. Genetics of amyotrophic lateral sclerosis: an update. Mol Neurodegener. 2013;8:28.

42. Lu H, Le WD, Xie YY, Wang XP. Current therapy of drugs in amyotrophic lateral sclerosis. Curr Neuropharmacol. 2016;14:314-21.

43. van Eijk RPA; Eijkemans MJC; Nikolakopoulos S; Jansen MD; Westeneng HJ van Eijk KR, et al. Pharmacogenetic interactions in amyotrophic lateral sclerosis: a step closer to a cure? Pharmacogenomics J. 2020;20:220-6.

44. Rothstein JD. Edaravone: A new drug approved for ALS. Cell. 2017;171:725.

45. Scott A. Drug therapy: on the treatment trail for ALS. Nature. 2017;550:120-1.

46. Fang $\mathrm{T}$, Al Khleifat A, Meurgey JH, Jones A, Leigh PN, Bensimon G, et al. Stage at which riluzole treatment prolongs survival in patients with amyotrophic lateral sclerosis: a retrospective analysis of data from a doseranging study. Lancet Neurol. 2018;17:416-22.

47. Zoing MC, Burke D, Pamphlett R, Kiernan MC. Riluzole therapy for motor neurone disease: an early Australian experience (1996-2002). J Clin Neurosci. 2006;13:78-83

48. Traynor BJ, Alexander M, Corr B, Frost E, Hardiman O. An outcome study of riluzole in amyotrophic lateral sclerosis-a population-based study in Ireland, 1996-2000. J Neurol. 2003;250:473-9.

49. Chen L, Liu X, Tang L, Zhang N, Fan D. Long-term use of riluzole could improve the prognosis of sporadic amyotrophic lateral sclerosis patients: a real-world cohort study in China. Front Aging Neurosci. 2016;8:246.

50. Kiernan MC. Motor neuron disease in 2017: Progress towards therapy in motor neuron disease. Nat Rev Neurol. 2018:14:65-6.

51. Yoshino H, Kimura A. Investigation of the therapeutic effects of edaravone, a free radical scavenger, on amyotrophic lateral sclerosis (phase II study). Amyotroph Lateral Scler. 2006;7:241-5.

52. Takahashi F, Takei K, Tsuda K, Palumbo J. Post-hoc analysis of MCl186-17, the extension study to MCl186-16, the confirmatory double-blind, parallelgroup, placebo-controlled study of edaravone in amyotrophic lateral sclerosis. Amyotroph Lateral Scler Frontotemporal Degener. 2017;18:32-9.

53. Lunetta C, Moglia C, Lizio A, Caponnetto C, Dubbioso R, Giannini F, et al. The Italian multicenter experience with edaravone in amyotrophic lateral sclerosis. J Neurol. 2020;267:3258-67.

54. Jackson CE, Gronseth G, Rosenfeld J, Barohn RJ, Dubinsky R, Simpson CB, et al. Randomized double-blind study of botulinum toxin type B for sialorrhea in ALS patients. Muscle Nerve. 2009;39:137-43.

55. Pioro EP, Brooks BR, Cummings J, Schiffer R, Thisted RA, Wynn D, et al. Dextromethorphan plus ultra low-dose quinidine reduces pseudobulbar affect. Ann Neurol. 2010;68:693-702.

56. Andersen PM, Abrahams S, Borasio GD, de Carvalho M, Chio A, Van Damme P, et al. EFNS guidelines on the clinical management of amyotrophic lateral sclerosis (MALS)-revised report of an EFNS task force. Eur J Neurol. 2012:19:360-75.

57. McClelland S 3rd, Bethoux FA, Boulis NM, Sutliff MH, Stough DK, Schwetz $\mathrm{KM}$, et al. Intrathecal baclofen for spasticity-related pain in amyotrophic lateral sclerosis: efficacy and factors associated with pain relief. Muscle Nerve 2008:37:396-8.

58. Whiting PF, Wolff RF, Deshpande S, Di Nisio M, Duffy S, Hernandez AV, et al. Cannabinoids for medical use: a systematic review and meta-analysis. JAMA 2015;313:2456-73. 
59. Friedman D, French JA, Maccarrone M. Safety, efficacy, and mechanisms of action of cannabinoids in neurological disorders. Lancet Neurol. 2019;18: 504-12.

60. Riva N, Mora G, Sorarù G, Lunetta C, Ferraro OE, Falzone Y, et al. Safety and efficacy of nabiximols on spasticity symptoms in patients with motor neuron disease (CANALS): a multicentre, double-blind, randomised, placebocontrolled, phase 2 trial. Lancet Neurol. 2019;18:155-64.

61. Meyer T, Funke A, Münch C, Kettemann D, Maier A, Walter B, et al. Real world experience of patients with amyotrophic lateral sclerosis (ALS) in the treatment of spasticity using tetrahydrocannabinol:cannabidiol (THC:CBD). BMC Neurol. 2019;19:222.

62. Espejo-Porras F, García-Toscano L, Rodríguez-Cueto C, Santos-García I, de Lago E, Fernandez-Ruiz J. Targeting glial cannabinoid CB(2) receptors to delay the progression of the pathological phenotype in TDP-43 (A315T) transgenic mice, a model of amyotrophic lateral sclerosis. Br J Pharmacol. 2019;176:1585-600.

63. Rodríguez-Cueto C, García-Toscano L, Santos-García I, Gómez-Almería M, Gonzalo-Consuegra C, Espejo-Porras F, et al. Targeting the CB(2) receptor and other endocannabinoid elements to delay disease progression in amyotrophic lateral sclerosis. Br J Pharmacol. 2021;178:1373-87.

64. Urbi B, Owusu MA, Hughes I, Katz M, Broadley S, Sabet A. Effects of cannabinoids in amyotrophic lateral sclerosis (ALS) murine models: a systematic review and meta-analysis. J Neurochem. 2019;149:284-97.

65. Bourke SC, Tomlinson M, Williams TL, Bullock RE, Shaw PJ, Gibson GJ. Effects of non-invasive ventilation on survival and quality of life in patients with amyotrophic lateral sclerosis: a randomised controlled trial. Lancet Neurol. 2006;5:140-7.

66. DiPALS Writing Committee, DiPALS Study Group Collaborators. Safety and efficacy of diaphragm pacing in patients with respiratory insufficiency due to amyotrophic lateral sclerosis (DiPALS): a multicentre, open-label, randomised controlled trial. Lancet Neurol. 2015;14:883-92.

67. Gonzalez-Bermejo J, Morélot-Panzini C, Tanguy ML, Meininger V, Pradat PF, Lenglet T, et al. Early diaphragm pacing in patients with amyotrophic lateral sclerosis (RespiStimALS): a randomised controlled triple-blind trial. Lancet Neurol. 2016;15:1217-27.

68. Oskarsson B, Moore D, Mozaffar T, Ravits J, Wiedau-Pazos M, Parziale N, et al. Mexiletine for muscle cramps in amyotrophic lateral sclerosis: A randomized, double-blind crossover trial. Muscle Nerve. 2018;58:42-8.

69. Adiao KJB, Espiritu Al, Bagnas MAC. Efficacy and safety of mexiletine in amyotrophic lateral sclerosis: a systematic review of randomized controlled trials. Neurodegener Dis Manag. 2020;10:397-407.

70. Kellogg J, Bottman L, Arra EJ, Selkirk SM, Kozlowski F. Nutrition management methods effective in increasing weight, survival time and functional status in ALS patients: a systematic review. Amyotroph Lateral Scler Frontotemporal Degener. 2018;19:7-11.

71. ProGas Study Group. Gastrostomy in patients with amyotrophic lateral sclerosis (ProGas): a prospective cohort study. Lancet Neurol. 2015;14:702-9.

72. Yu H, Kim SH, Noh MY, Lee S, Park Y. Relationship between dietary fiber intake and the prognosis of amytrophic lateral sclerosis in Korea. Nutrients. 2020;12:3420.

73. Chen S, Zhang X, Song L, Le W. Autophagy dysregulation in amyotrophic lateral sclerosis. Brain Pathol. 2012;22:110-6.

74. Zhang X, Li L, Chen S, Yang D, Wang Y, Zhang X, et al. Rapamycin treatment augments motor neuron degeneration in SOD1(G93A) mouse model of amyotrophic lateral sclerosis. Autophagy. 2011;7:412-25.

75. Wang IF, Guo BS, Liu YC, Wu CC, Yang CH, Tsai KJ, et al. Autophagy activators rescue and alleviate pathogenesis of a mouse model with proteinopathies of the TAR DNA-binding protein 43. Proc Natl Acad Sci U S A. 2012;109:15024-9.

76. Lattante S, de Calbiac H, Le Ber I, Brice A, Ciura S, Kabashi E. Sqstm1 knockdown causes a locomotor phenotype ameliorated by rapamycin in a zebrafish model of ALS/FTLD. Hum Mol Genet. 2015;24:1682-90.

77. Castillo K, Nassif M, Valenzuela V, Rojas F, Matus S, Mercado G, et al. Trehalose delays the progression of amyotrophic lateral sclerosis by enhancing autophagy in motoneurons. Autophagy. 2013;9:1308-20.

78. Zhang $X$, Chen S, Song L, Tang Y, Shen Y, Jia L, et al. MTOR-independent, autophagic enhancer trehalose prolongs motor neuron survival and ameliorates the autophagic flux defect in a mouse model of amyotrophic lateral sclerosis. Autophagy. 2014;10:588-602.

79. Li Y, Guo Y, Wang X, Yu X, Duan W, Hong K, et al. Trehalose decreases mutant SOD1 expression and alleviates motor deficiency in early but not end-stage amyotrophic lateral sclerosis in a SOD1-G93A mouse model. Neuroscience. 2015;298:12-25.

80. Fornai F, Longone P, Cafaro L, Kastsiuchenka O, Ferrucci M, Manca ML, et al. Lithium delays progression of amyotrophic lateral sclerosis. Proc Natl Acad Sci U S A. 2008;105:2052-7.

81. Fornai $F$, Longone $P$, Ferrucci $M$, Lenzi $P$, Isidoro C, Ruggieri S, et al. Autophagy and amyotrophic lateral sclerosis: the multiple roles of lithium. Autophagy. 2008:4:527-30.

82. Guo F, Liu X, Cai H, Le W. Autophagy in neurodegenerative diseases: pathogenesis and therapy. Brain Pathol. 2018;28:3-13.

83. Miller RG, Jackson CE, Kasarskis EJ, England JD, Forshew D, Johnston W, et al. Practice parameter update: the care of the patient with amyotrophic lateral sclerosis: drug, nutritional, and respiratory therapies (an evidencebased review): report of the quality standards Subcommittee of the American Academy of neurology. Neurology. 2009;73:1218-26.

84. Miller RG, Moore DH, Forshew DA, Katz JS, Barohn RJ, Valan M, et al. Phase II screening trial of lithium carbonate in amyotrophic lateral sclerosis: examining a more efficient trial design. Neurology. 2011;77:973-9.

85. Verstraete $\mathrm{E}$, Veldink JH, Huisman MH, Draak T, Uijtendaal EV, van der Kooi $\mathrm{A}$, et al. Lithium lacks effect on survival in amyotrophic lateral sclerosis: a phase IIb randomised sequential trial. J Neurol Neurosurg Psychiatry. 2012; 83:557-64.

86. Aggarwal SP, Zinman L, Simpson E, McKinley J, Jackson KE, Pinto H, et al. Safety and efficacy of lithium in combination with riluzole for treatment of amyotrophic lateral sclerosis: a randomised, double-blind, placebocontrolled trial. Lancet Neurol. 2010;9:481-8.

87. Morrison KE, Dhariwal S, Hornabrook R, Savage L, Burn DJ, Khoo TK, et al. Lithium in patients with amyotrophic lateral sclerosis (LiCALS): a phase 3 multicentre, randomised, double-blind, placebo-controlled trial. Lancet Neurol. 2013;12:339-45.

88. van Eijk RPA, Jones AR, Sproviero W, Shatunov A, Shaw PJ, Leigh PN, et al. Metaanalysis of pharmacogenetic interactions in amyotrophic lateral sclerosis clinical trials. Neurology. 2017;89:1915-22.

89. Chiu SC, Chen SP, Huang SY, Wang MJ, Lin SZ, Harn HJ, et al. Induction of apoptosis coupled to endoplasmic reticulum stress in human prostate cancer cells by n-butylidenephthalide. PLoS One. 2012;7:e33742.

90. Hsueh KW, Chiou TW, Chiang SF, Yamashita T, Abe K, Borlongan CV, et al. Autophagic down-regulation in motor neurons remarkably prolongs the survival of ALS mice. Neuropharmacology. 2016;108:152-60.

91. Zhou QM, Zhang JJ, Li S, Chen S, Le WD. N-butylidenephthalide treatment prolongs life span and attenuates motor neuron loss in SOD1(G93A) mouse model of amyotrophic lateral sclerosis. CNS Neurosci Ther. 2017:23:375-85.

92. Schiebler M, Brown K, Hegyi K, Newton SM, Renna M, Hepburn L, et al. Functional drug screening reveals anticonvulsants as enhancers of mTORindependent autophagic killing of $M$. tuberculosis through inositol depletion. EMBO Mol Med. 2015;7:127-39.

93. Zhang JJ, Zhou QM, Chen S, Le WD. Repurposing carbamazepine for the treatment of amyotrophic lateral sclerosis in SOD1-G93A mouse model. CNS Neurosci Ther. 2018:24:1163-74.

94. Swarup V, Phaneuf D, Dupre N, Petri S, Strong M, Kriz J, et al. Deregulation of TDP-43 in amyotrophic lateral sclerosis triggers nuclear factor kappaBmediated pathogenic pathways. J Exp Med. 2011;208:2429-47.

95. Patel $P$, Julien JP, Kriz J. Early-stage treatment with Withaferin A reduces levels of misfolded superoxide dismutase 1 and extends lifespan in a mouse model of amyotrophic lateral sclerosis. Neurotherapeutics. 2015;12:217-33.

96. Li X, Zhu F, Jiang J, Sun C, Zhong Q, Shen M, et al. Simultaneous inhibition of the ubiquitin-proteasome system and autophagy enhances apoptosis induced by ER stress aggravators in human pancreatic cancer cells. Autophagy. 2016;12:1521-37.

97. Dutta K, Patel P, Rahimian R, Phaneuf D, Julien JP. Withania somnifera reverses transactive response dna binding protein 43 proteinopathy in a mouse model of amyotrophic lateral sclerosis/frontotemporal lobar degeneration. Neurotherapeutics. 2017;14:447-62.

98. Dutta K, Patel P, Julien J-P. Protective effects of Withania somnifera extract in SOD1G93A mouse model of amyotrophic lateral sclerosis. Exp Neurol. 2018;309:193-204

99. Zhang X, Chen S, Lu K, Wang F, Deng J, Xu Z, et al. Verapamil ameliorates motor neuron degeneration and improves lifespan in the SOD1(G93A) mouse model of ALS by enhancing autophagic flux. Aging Dis. 2019;10:1159-73.

100. Mackenzie IR, Rademakers R, Neumann M. TDP-43 and FUS in amyotrophic lateral sclerosis and frontotemporal dementia. Lancet Neurol. 2010:9.9951007. 
101. Marrone L, Poser I, Casci I, Japtok J, Reinhardt P, Janosch A, et al. Isogenic FUS-eGFP iPSC reporter lines enable quantification of FUS stress granule pathology that is rescued by drugs inducing autophagy. Stem Cell Reports. 2018;10:375-89.

102. Okano H, Yasuda D, Fujimori K, Morimoto S, Takahashi S. Ropinirole, a new ALS drug candidate developed using iPSCs. Trends Pharmacol Sci. 2020;41: 99-109.

103. Imamura K, Izumi Y, Watanabe A, Tsukita K, Woltjen K, Yamamoto T, et al. The Src/c-Abl pathway is a potential therapeutic target in amyotrophic lateral sclerosis. Sci Transl Med. 2017;9:eaaf3962.

104. Gal J, Chen J, Barnett KR, Yang L, Brumley E, Zhu H. HDAC6 regulates mutant SOD1 aggregation through two SMIR motifs and tubulin acetylation. J Biol Chem. 2013;288:15035-45.

105. Kawaguchi Y, Kovacs JJ, McLaurin A, Vance JM, Ito A, Yao TP. The deacetylase HDAC6 regulates aggresome formation and cell viability in response to misfolded protein stress. Cell. 2003;115:727-38.

106. Lee JY, Koga H, Kawaguchi Y, Tang W, Wong E, Gao YS, et al. HDAC6 controls autophagosome maturation essential for ubiquitin-selective qualitycontrol autophagy. EMBO J. 2010;29:969-80.

107. Chen S, Zhang XJ, Li LX, Wang Y, Zhong RJ, Le W. Histone deacetylase 6 delays motor neuron degeneration by ameliorating the autophagic flux defect in a transgenic mouse model of amyotrophic lateral sclerosis. Neurosci Bull. 2015;31:459-68.

108. Taes I, Timmers M, Hersmus N, Bento-Abreu A, Van Den Bosch L, Van Damme $P$, et al. Hdac6 deletion delays disease progression in the SOD1G93A mouse model of ALS. Hum Mol Genet. 2013;22:1783-90.

109. Bonner JF, Blesch A, Neuhuber B, Fischer I. Promoting directional axon growth from neural progenitors grafted into the injured spinal cord. J Neurosci Res. 2010;88:1182-92.

110. Boulis NM, Federici T, Glass JD, Lunn JS, Sakowski SA, Feldman EL. Translational stem cell therapy for amyotrophic lateral sclerosis. Nat Rev Neurol. 2011:8:172-6.

111. Chen KS, Sakowski SA, Feldman EL. Intraspinal stem cell transplantation for amyotrophic lateral sclerosis. Ann Neurol. 2016;79:342-53.

112. Zalfa C, Rota Nodari L, Vacchi E, Gelati M, Profico D, Boido M, et al. Transplantation of clinical-grade human neural stem cells reduces neuroinflammation, prolongs survival and delays disease progression in the SOD1 rats. Cell Death Dis. 2019;10:345.

113. Thomsen GM, Avalos P, Ma AA, Alkaslasi M, Cho N, Wyss L, et al. Transplantation of neural progenitor cells expressing glial cell line-derived neurotrophic factor into the motor cortex as a strategy to treat amyotrophic lateral sclerosis. Stem Cells. 2018;36:1122-31.

114. Sironi F, Vallarola A, Violatto MB, Talamini L, Freschi M, De Gioia R, et al. Multiple intracerebroventricular injections of human umbilical cord mesenchymal stem cells delay motor neurons loss but not disease progression of SOD1G93A mice. Stem Cell Res. 2017;25:166-78.

115. Mazzini L, Ferrero I, Luparello V, Rustichelli D, Gunetti M, Mareschi K, et al. Mesenchymal stem cell transplantation in amyotrophic lateral sclerosis: A phase I clinical trial. Exp Neurol. 2010;223:229-37.

116. Abati E, Bresolin N, Comi G, Corti S. Advances, challenges, and perspectives in translational stem cell therapy for amyotrophic lateral sclerosis. Mol Neurobiol. 2019;56:6703-15.

117. Garbuzova-Davis S, Shell R, Mustafa H, Hailu S, Willing AE, Sanberg PR, et al. Advancing stem cell therapy for repair of damaged lung microvasculature in amyotrophic lateral sclerosis. Cell Transplant. 2020;29:963689720913494.

118. Thonhoff JR, Simpson EP, Appel SH. Neuroinflammatory mechanisms in amyotrophic lateral sclerosis pathogenesis. Curr Opin Neurol. 2018;31:635-9.

119. Coque E, Salsac C, Espinosa-Carrasco G, Varga B, Degauque N, Cadoux M, et al. Cytotoxic CD8(+) T lymphocytes expressing ALS-causing SOD1 mutant selectively trigger death of spinal motoneurons. Proc Natl Acad Sci U S A. 2019;116:2312-7

120. Beers DR, Zhao W, Wang J, Zhang X, Wen S, Neal D, et al. ALS patients' regulatory $T$ lymphocytes are dysfunctional, and correlate with disease progression rate and severity. JCI Insight. 2017;2:e89530.

121. Appel SH, Engelhardt J, Henkel JS, Siklos L, Beers DR, Yen AA, et al. Hematopoietic stem cell transplantation in patients with sporadic amyotrophic lateral sclerosis. Neurology. 2008;71:1326-34.

122. Baloh RH, Glass JD, Svendsen CN. Stem cell transplantation for amyotrophic lateral sclerosis. Curr Opin Neurol. 2018;31:655-61.

123. Beers DR, Henkel JS, Zhao W, Wang J, Appel SH. CD4+ T cells support glial neuroprotection, slow disease progression, and modify glial morphology in an animal model of inherited ALS. Proc Natl Acad Sci U S A. 2008;105: 15558-63.

124. Goutman SA, Savelieff MG, Sakowski SA, Feldman EL. Stem cell treatments for amyotrophic lateral sclerosis: a critical overview of early phase trials. Expert Opin Investig Drugs. 2019;28:525-43.

125. Abdul Wahid SF, Law ZK, Ismail NA, Lai NM. Cell-based therapies for amyotrophic lateral sclerosis/motor neuron disease. Cochrane Database Syst Rev. 2019;12:Cd011742.

126. Al-Chalabi A, Brown RH Jr. Finding a treatment for ALS - will gene editing cut it? N Engl J Med. 2018:378:1454-6.

127. Lagier-Tourenne C, Baughn M, Rigo F, Sun S, Liu P, Li HR, et al. Targeted degradation of sense and antisense C9orf72 RNA foci as therapy for ALS and frontotemporal degeneration. Proc Natl Acad Sci U S A. 2013;110:45309.

128. Scoles DR, Pulst SM. Oligonucleotide therapeutics in neurodegenerative diseases. RNA Biol. 2018;15:707-14.

129. Winer L, Srinivasan D, Chun S, Lacomis D, Jaffa M, Fagan A, et al. SOD1 in cerebral spinal fluid as a pharmacodynamic marker for antisense oligonucleotide therapy. JAMA Neurol. 2013;70:201-7.

130. Selvaraj BT, Livesey MR, Zhao C, Gregory JM, James OT, Cleary EM, et al. C9ORF72 repeat expansion causes vulnerability of motor neurons to $\mathrm{ca}(2+$ )-permeable AMPA receptor-mediated excitotoxicity. Nat Commun. 2018;9:347.

131. Donnelly CJ, Zhang PW, Pham JT, Haeusler AR, Mistry NA, Vidensky S, et al. RNA toxicity from the ALS/FTD C9ORF72 expansion is mitigated by antisense intervention. Neuron. 2013;80:415-28.

132. Sareen D, O'Rourke JG, Meera P, Muhammad AK, Grant S, Simpkinson M, et al. Targeting RNA foci in iPSC-derived motor neurons from ALS patients with a C9ORF72 repeat expansion. Sci Transl Med. 2013;5:208ra149.

133. Jiang J, Zhu Q, Gendron TF, Saberi S, McAlonis-Downes M, Seelman A, et al. Gain of toxicity from ALS/FTD-linked repeat expansions in C9ORF72 is alleviated by antisense oligonucleotides targeting GGGGCC-containing RNAs. Neuron. 2016:90:535-50.

134. Becker LA, Huang B, Bieri G, Ma R, Knowles DA, Jafar-Nejad P, et al. Therapeutic reduction of ataxin-2 extends lifespan and reduces pathology in TDP-43 mice. Nature. 2017:544:367-71.

135. Bobbin ML, Rossi JJ. RNA interference (RNAi)-based therapeutics: delivering on the promise? Annu Rev Pharmacol Toxicol. 2016;56:103-22.

136. Jiang J, Ravits J. Pathogenic mechanisms and therapy development for C9orf72 amyotrophic lateral sclerosis/frontotemporal dementia. Neurotherapeutics. 2019;16: 1115-32.

137. Stoica L, Todeasa SH, Cabrera GT, Salameh JS, EIMallah MK, Mueller C, et al. Adeno-associated virus-delivered artificial microRNA extends survival and delays paralysis in an amyotrophic lateral sclerosis mouse model. Ann Neurol. 2016;79:687-700

138. Iannitti T, Scarrott JM, Likhite S, Coldicott IRP, Lewis KE, Heath PR, et al. Translating SOD1 gene silencing toward the clinic: a highly efficacious, offtarget-free, and biomarker-supported strategy for fALS. Mol Ther Nucleic Acids. 2018;12:75-88.

139. Martier R, Liefhebber JM, Garcia-Osta A, Miniarikova J, Cuadrado-Tejedor M, Espelosin M, et al. Targeting RNA-mediated toxicity in C9orf72 ALS and/or FTD by RNAi-based gene therapy. Mol Ther Nucleic Acids. 2019;16:26-37.

140. Martier R, Liefhebber JM, Miniarikova J, van der Zon T, Snapper J, Kolder I, et al. Artificial microRNAs targeting C9orf72 can reduce accumulation of intra-nuclear transcripts in ALS and FTD patients. Mol Ther Nucleic Acids. 2019;14:593-608.

141. Bravo-Hernandez M, Tadokoro T, Navarro MR, Platoshyn O, Kobayashi Y, Marsala S, et al. Spinal subpial delivery of AAV9 enables widespread gene silencing and blocks motoneuron degeneration in ALS. Nat Med. 2020;26: 118-30.

142. Mueller C, Berry JD, McKenna-Yasek DM, Gernoux G, Owegi MA, Pothier LM, et al. SOD1 suppression with adeno-associated virus and microrna in familial ALS. N Engl J Med. 2020;383:151-8.

143. Gaj T, Ojala DS, Ekman FK, Byrne LC, Limsirichai P, Schaffer DV. In vivo genome editing improves motor function and extends survival in a mouse model of ALS. Sci Adv. 2017:3:eaar3952.

144. Wang L, Yi F, Fu L, Yang J, Wang S, Wang Z, et al. CRISPR/Cas9-mediated targeted gene correction in amyotrophic lateral sclerosis patient iPSCs. Protein Cell. 2017:8:365-78.

145. Batra R, Nelles DA, Pirie E, Blue SM, Marina RJ, Wang $H$, et al. Elimination of toxic microsatellite repeat expansion RNA by RNA-targeting Cas9. Cell. 2017; 170:899-912. 
146. Pinto BS, Saxena T, Oliveira R, Mendez-Gomez HR, Cleary JD, Denes LT, et al. Impeding transcription of expanded microsatellite repeats by deactivated Cas9. Mol Cell. 2017;68:479-90.

147. Andrade NS, Ramic M, Esanov R, Liu W, Rybin MJ, Gaidosh G, et al. Dipeptide repeat proteins inhibit homology-directed DNA double strand break repair in C9ORF72 ALS/FTD. Mol Neurodegener. 2020;15:13.

148. Nguyen HP, Van Broeckhoven C, van der Zee J. ALS genes in the genomic era and their implications for FTD. Trends Genet. 2018;34:404-23.

149. Veldink JH. ALS genetic epidemiology 'How simplex is the genetic epidemiology of ALS?'. J Neurol Neurosurg Psychiatry. 2017;88:537.

150. Cady J, Allred P, Bali T, Pestronk A, Goate A, Miller TM, et al. Amyotrophic lateral sclerosis onset is influenced by the burden of rare variants in known amyotrophic lateral sclerosis genes. Ann Neurol. 2015;77:100-13.

151. Szeto HH. Mitochondria-targeted peptide antioxidants: novel neuroprotective agents. AAPS J. 2006;8:E521-31.

152. Cassina P, Cassina A, Pehar M, Castellanos R, Gandelman M, de León A, et al. Mitochondrial dysfunction in SOD1G93A-bearing astrocytes promotes motor neuron degeneration: prevention by mitochondrial-targeted antioxidants. J Neurosci. 2008:28:4115-22.

153. Miquel E, Cassina A, Martínez-Palma L, Souza JM, Bolatto C, Rodríguez Bottero S, et al. Neuroprotective effects of the mitochondria-targeted antioxidant MitoQ in a model of inherited amyotrophic lateral sclerosis. Free Radic Biol Med. 2014;70:204-13.

154. Akaike A, Tamura Y, Sato Y, Yokota T. Protective effects of a vitamin B12 analog, methylcobalamin, against glutamate cytotoxicity in cultured cortical neurons. Eur J Pharmacol. 1993;241:1-6.

155. Zhang X, Chen S, Li L, Wang Q, Le W. Folic acid protects motor neurons against the increased homocysteine, inflammation and apoptosis in SOD1 G93A transgenic mice. Neuropharmacology. 2008;54:1112-9.

156. Ikeda K, Iwasaki Y, Kaji R. Neuroprotective effect of ultra-high dose methylcobalamin in wobbler mouse model of amyotrophic lateral sclerosis. J Neurol Sci. 2015;354:70-4

157. Waibel S, Reuter A, Malessa S, Blaugrund E, Ludolph AC. Rasagiline alone and in combination with riluzole prolongs survival in an ALS mouse model J Neurol. 2004;251:1080-4.

158. Paganoni S, Macklin EA, Hendrix S, Berry JD, Elliott MA, Maiser S, et al. Tria of sodium phenylbutyrate-taurursodiol for amyotrophic lateral sclerosis. $\mathrm{N}$ Engl J Med. 2020;383:919-30.

159. Paganoni S, Hendrix S, Dickson SP, Knowlton N, Macklin EA, Berry JD, et al. Long-term survival of participants in the CENTAUR trial of sodium phenylbutyrate-taurursodiol in amyotrophic lateral sclerosis. Muscle Nerve. 2021;63:31-9.

160. Wang GY, Rayner SL, Chung R, Shi BY, Liang XJ. Advances in nanotechnology-based strategies for the treatments of amyotrophic lateral sclerosis. Mater Today Bio. 2020;6:100055.

161. Bordoni M, Scarian E, Rey F, Gagliardi S, Carelli S, Pansarasa O, et al. Biomaterials in neurodegenerative disorders: a promising therapeutic approach. Int J Mol Sci. 2020;21:3243

162. Bondi ML, Craparo EF, Giammona G, Drago F. Brain-targeted solid lipid nanoparticles containing riluzole: preparation, characterization and biodistribution. Nanomedicine (London). 2010;5:25-32.

163. Verma SK, Arora I, Javed K, Akhtar M, Samim M. Enhancement in the neuroprotective power of riluzole against cerebral ischemia using a brain targeted drug delivery vehicle. ACS Appl Mater Interfaces. 2016;8:19716-23.

164. Yang T, Ferrill L, Gallant L, McGillicuddy S, Fernandes T, Schields N, et al. Verapamil and riluzole cocktail liposomes overcome pharmacoresistance by inhibiting P-glycoprotein in brain endothelial and astrocyte cells: A potent approach to treat amyotrophic lateral sclerosis. Eur J Pharm Sci. 2018;120: 30-9.

165. Jin Q, Cai Y, Li S, Liu H, Zhou X, Lu C, et al. Edaravone-encapsulated agonistic micelles rescue ischemic brain tissue by tuning blood-brain barrier permeability. Theranostics. 2017;7:884-98.

166. Chen L, Watson C, Morsch M, Cole NJ, Chung RS, Saunders DN, et al. Improving the delivery of SOD1 antisense oligonucleotides to motor neurons using calcium phosphate-lipid nanoparticles. Front Neurosci. 2017; 11:476.

167. Walczak P, Wojtkiewicz J, Nowakowski A, Habich A, Holak P, Xu J, et al. Realtime MRI for precise and predictable intra-arterial stem cell delivery to the central nervous system. J Cereb Blood Flow Metab. 2017;37:2346-58.
168. Malysz-Cymborska I, Golubczyk D, Kalkowski L, Burczyk A, Janowski M, Holak $P$, et al. MRI-guided intrathecal transplantation of hydrogel-embedded glial progenitors in large animals. Sci Rep. 2018;8:16490.

169. Vieira S, Strymecka P, Stanaszek L, Silva-Correia J, Drela K, Fiedorowicz M, et al. Methacrylated gellan gum and hyaluronic acid hydrogel blends for image-guided neurointerventions. J Mater Chem B. 2020:8:5928-37.

\section{Ready to submit your research? Choose BMC and benefit from:}

- fast, convenient online submission

- thorough peer review by experienced researchers in your field

- rapid publication on acceptance

- support for research data, including large and complex data types

- gold Open Access which fosters wider collaboration and increased citations

- maximum visibility for your research: over $100 \mathrm{M}$ website views per year

At $\mathrm{BMC}$, research is always in progress.

Learn more biomedcentral.com/submissions 